\title{
Morphogenesis of neurons and glia within an epithelium
}

\author{
Isabel I. C. Low ${ }^{1,2}$, Claire R. Williams ${ }^{1,2}$, Megan K. Chong ${ }^{2}$, Ian G. McLachlan², \\ Bradley M. Wierbowski ${ }^{2}$, Irina Kolotuev ${ }^{3,4}$, and Maxwell G. Heiman ${ }^{2,5}$
}

${ }^{1}$ These authors contributed equally to this work.

${ }^{2}$ Department of Genetics, Harvard Medical School and Boston Children's Hospital, Boston MA

${ }^{3}$ Université de Rennes 1, Plateforme microscopie électronique, Rennes, France

${ }^{4}$ Current address: Electron Microscopy Facility, University of Lausanne, 1015 Lausanne,

Switzerland.

${ }^{5}$ To whom correspondence should be addressed: heiman@genetics.med.harvard.edu

Running title: Morphogenesis of epithelial neurons 


\section{ABSTRACT}

To sense the outside world, some neurons protrude across epithelia, the cellular barriers that line every surface of our bodies. To study the morphogenesis of such neurons, we examined the C. elegans amphid, in which dendrites protrude through a glial channel at the nose. During development, amphid dendrites extend by attaching to the nose via DYF-7, a type of protein typically found in epithelial apical ECM. Here, we show that amphid neurons and glia exhibit epithelial properties, including tight junctions and apical-basal polarity, and develop in a manner resembling other epithelia. We find that DYF-7 is a fibril-forming apical ECM component that prevents rupture of the tube-shaped glial channel, reminiscent of roles for apical ECM in other narrow epithelial tubes. We also identify a role for FRM-2, a homolog of EPBL15/moe/Yurt which promote epithelial integrity in other systems. Finally, we show that other environmentally-exposed neurons share a requirement for DYF-7. Together, our results suggest that these neurons and glia can be viewed as part of an epithelium continuous with the skin, and are shaped by mechanisms shared with other epithelia. 


\section{INTRODUCTION}

Between each of us and the outer world sits an epithelium. These sheets of cells, held together by tight and adherens junctions, create a barrier at every surface of our body and provide the interface through which we perceive our surroundings.

Neurons form intimate connections with epithelia in order to transmit information from the exterior surfaces of the body to the brain. For example, our sense of touch is mediated by mechanosensory neurons that branch along the basal ("inner") side of the skin epithelium. The skin plays a major role in shaping these sensory neurons, and these epithelia-neuron interactions have been extensively studied in vertebrates (Wang et al., 2013; Zimmerman et al., 2014), Drosophila (Parrish et al., 2009; Han et al., 2012; Kim et al., 2012; Jiang et al., 2014; Tenenbaum et al., 2017), and C. elegans (Dong et al., 2013; Liang et al., 2015; Díaz-Balzac et al., 2016; Liu et al., 2016; Zou et al., 2016; Zhu et al., 2017; Celestrin et al., 2018). Similarly, our senses of hearing and taste are mediated by afferent neurons that are positioned at the basal surfaces of epithelia and receive information from specialized non-neuronal sensory cells (hair cells, taste cells) within these epithelia (Roper, 2013; Frank and Goodrich, 2018). In each of these examples, neurons make intimate connections with epithelia, but they remain restricted to the "inside" surface and do not directly contact the outside world.

In contrast, our sense of smell is mediated by sensory neurons with a different topology: they protrude through the epithelium to the apical ("outside") surface where they detect odorants in the outside world (Firestein, 2001). On one side, the neurons extend dendrites that form tight junctions with glial-like cells in the epithelium (Steinke et al., 2008). On the other side, the neurons extend axons that pierce the basal lamina of the epithelium and extend into the brain (Graziadei and Graziadei, 1979). Thus, based on their anatomy, these sensory neurons have properties of both epithelial cells and neurons - like an epithelial cell, they have an outwardfacing surface exposed to the environment but, like a true neuron, they have an axon that projects 
into the brain. Sensory neurons with this anatomy are prevalent in invertebrates, and might represent an ancestral sensory structure (McLachlan and Heiman, 2013). In most cases, they are surrounded by glial supporting cells that are also exposed to the outside environment. These interesting structures raise several questions. Do the neurons and glia exhibit other epitheliallike properties, such as apical-basal polarity? Do they develop using mechanisms of morphogenesis that are similar to those used by epithelia? What role do the glia play during neuron development?

Here, we address these questions using the $C$. elegans amphid, which consists of 12 neurons and two glial cells (Ward et al., 1975). Each neuron extends an unbranched dendrite to the nose where it senses environmental stimuli, as well as an axon that projects into the nerve ring, or "brain" (White et al., 1986). The two glial cells, called the sheath and socket, each extend a single process to the nose where they form a tube-shaped pore through which most of the dendrites have direct access to the outside environment (Ward et al., 1975). The sheath completely wraps the dendrite endings, creating a local environment that can affect sensory function (Perens and Shaham, 2005; Bacaj et al., 2008; Wang et al., 2008; Oikonomou et al., 2011; Procko et al., 2011; Oikonomou et al., 2012; Singhvi et al., 2016; Wallace et al., 2016; Wang et al., 2017), while the socket forms an opening continuous with the skin. The dendrite endings protrude through this tube-shaped glial pore into the environment, and are decorated with cilia bearing receptors for specific smells, tastes, or other stimuli (Bargmann, 2006).

In the embryo, the amphid dendrites develop by a mechanism called retrograde extension, which is distinct from the typical growth-cone-mediated outgrowth of axons or dendrites (Heiman and Shaham, 2009). First, amphid neurons and glia are assembled into a polarized multicellular rosette that is carried to the nose by the migrating skin epithelium (Fan et al., 2018). Then, the nascent tips of the amphid dendrites stay anchored at the nose while the neuronal cell bodies migrate away, stretching the dendrites out behind them (Heiman and Shaham, 2009). 
DYF-7, a zona pellucida (ZP) domain protein, is required to keep the dendrite tips anchored at the nose; in the absence of DYF-7, the nascent dendrites are dragged along behind the migrating neuronal cell bodies and fail to extend (Heiman and Shaham, 2009). Interestingly, ZP domain proteins like DYF-7 are typically associated with epithelia, rather than with developing neurons (Plaza et al., 2010). They are almost always found in the apical extracellular matrix (ECM), which coats the outer (or luminal) surfaces of epithelia in the kidney, liver, and many other tissues. ZP domain proteins, along with other apical ECM proteins, play important roles in shaping epithelia, especially narrow epithelial tubes (Sundaram and Cohen, 2017). This led us to consider whether epithelial features of amphid neurons and glia might be important for their development.

Here, we show that amphid neurons and glia exhibit hallmarks of epithelial cells, including tight junctions and apical-basal polarity. Consistent with the idea that DYF-7 acts as a component of apical ECM, we find that it forms fibrils at the apical surface of the developing amphid. Loss of DYF-7 leads to rupture of the tube-shaped glial pore that surrounds the dendrites, reminiscent of rupture defects seen in other epithelial tubes upon disrupting apical ECM. These defects are exacerbated by loss of FRM-2, a homolog of proteins that are also involved in epithelial integrity in other systems. Finally, we show that a requirement for DYF-7 is shared by other sensory neurons that are exposed to the environment. Our results suggest that these environmentally-exposed sensory neurons and their associated glia should be viewed as part of an epithelium that is continuous with the skin, with apical-basal polarity and a mechanism of development that shares key features with other epithelia, especially narrow epithelial tubes. 


\section{RESULTS}

\section{Amphid neurons and glia exhibit hallmarks of an epithelium}

In the mature amphid, dendrites are exposed to the environment through a tube-shaped glial pore (Fig. 1A-D). We asked whether amphid neurons and glia exhibit properties of true epithelial cells, namely the presence of tight junctions and apical-basal polarity.

Tight junctions. Classical EM analysis described electron-dense tight junctions between amphid neurons and the sheath glial cell; the sheath and socket glia; and the socket and skin (Ward et al., 1975; Perkins et al., 1986). Consistent with these observations, recent studies noted localization of the tight junction protein AJM-1 near amphid dendrite endings (Nguyen et al., 2014; Nechipurenko et al., 2016). We used promoters specific to the ASE neuron, the sheath, or the socket (gcy-5pro, F16F9.3pro, and grl-2pro, respectively; Fig. 1D) to drive expression of a portion of AJM-1 cDNA tagged with CFP or YFP in each of these cell types. This approach allowed us to visualize defined tight junctions with single-cell resolution.

AJM-1-YFP expressed in the sheath glial cell labeled 13 ring-shaped junctions (Fig. 1E, yellow). Their positions suggest a single large junction to the socket plus 12 smaller junctions to each of the dendrites. The ASE dendrite passes through one of these smaller rings (Fig. 1E, red). AJM-1-CFP expressed in the ASE neuron labels a ring that is concentric with one of the sheath rings and is positioned near the dendrite ending, proximal to the cilium (Fig. 1E, arrowhead). We obtained similar results with other amphid neurons (AWB and AWC; Supp. Fig. S1A). These results indicate that each neuron forms an individual ring-shaped tight junction with the sheath glial cell.

AJM-1-CFP expressed in the socket glial cell labels two ring-shaped structures whose positions are consistent with the presence of socket:skin and socket:sheath junctions (Fig. 1F, blue). The latter overlaps AJM-1-YFP expressed in the sheath glial cell (Fig. 1F, yellow). AJM1-CFP also labels a stripe connecting these rings, consistent with the auto-junction that the 
socket makes on itself as it wraps into a single-cell tube (Fig. 1B,F). We obtained similar results using another tight junction component (DLG-1, Supp. Fig. S1B). Together, the neuron:sheath, sheath:socket, and socket:skin tight junctions delineate an outward-facing surface continuous with the skin epithelium (Fig. 1B).

Apical-basal polarity. Another hallmark of epithelia is the presence of biochemically distinct apical and basolateral membranes. We recently developed constructs derived from the transmembrane protein SAX-7 that localize exclusively apically or basolaterally in epithelia (Supp. Fig. S1D). For simplicity, we will refer to these markers as ApiGreen and BasoRed. We expressed these markers under control of promoters specific to single amphid neurons or glia.

In the neuron, ApiGreen localized distal to the tight junction in the dendrite ending (Fig. 1G, green). BasoRed localized along the length of the dendrite and was excluded from the dendrite ending (Fig. 1G, red). This suggests that the outward- and inward-facing surfaces of the neuron are biochemically distinct. The region labeled by ApiGreen has been referred to as the periciliary membrane compartment (PCMC) and is a site of membrane trafficking important for ciliogenesis (Blacque and Sanders, 2014). ApiGreen was typically, but not always, excluded from the cilium; in general, transmembrane proteins are excluded from the cilium via a diffusion barrier called the ciliary gate (Garcia-Gonzalo and Reiter, 2017) but higher expression levels of ApiGreen may have allowed it to leak through this barrier in some cases.

In the sheath glial cell, ApiGreen localized to the outward-facing surface between the sheath:neuron and sheath:socket junctions (Fig. 1H, green). A marker of apical cytoskeleton, ERM-1, localized in the same pattern (Supp. Fig. S1C). BasoRed localized to the rest of the glial surface and did not overlap with ApiGreen (Fig. 1H, red). Similarly, in the socket glial cell, ApiGreen localized to the outward-facing surface between the sheath:socket and socket:skin junctions, with BasoRed localizing to the rest of the glial surface (Fig. 1C,I). 
Together, the presence of tight junctions and apical-basal polarity suggest that amphid neurons and glia can be viewed as part of an epithelium continuous with the skin.

\section{DYF-7 is an apical ECM component that prevents rupture of the amphid epithelium}

Next, we considered how the epithelial properties of these neurons and glia might relate to their morphogenesis in the embryo. We previously found that the ZP domain protein DYF-7 is required for amphid dendrite extension during development. Most ZP domain proteins are found at the apical surfaces of epithelia, where they polymerize into fibrils and play important roles in epithelial morphogenesis, including preventing rupture of narrow epithelial tubes (Plaza et al., 2010). Viewing the amphid neurons and glia as part of an epithelium, we tested three predictions about DYF-7: first, that it localizes to apical surfaces; second, that it polymerizes into fibrils; and third, that defects caused by loss of DYF-7 reflect epithelial rupture.

DYF-7 localizes to apical surfaces. We examined the localization of DYF-7 in the developing amphid and other tissues. Most ZP domain proteins are synthesized with a membrane anchor and undergo proteolytic cleavage at a consensus furin cleavage site (CFCS) to release the ectodomain (Bokhove and Jovine, 2018). DYF-7 contains a CFCS and can undergo proteolytic cleavage in vitro (Heiman and Shaham, 2009). In order to determine whether DYF-7 undergoes cleavage in vivo and to track the localization of its ectodomain, we tagged DYF-7 with superfolderGFP (sfGFP) on its ectodomain (DYF-7 ${ }^{\text {ecto }}$ ) and mCherry on its cytoplasmic tail (DYF-7 ${ }^{\text {cyt }}$ (Fig. 2A). This construct completely rescues a $d y f-7$ null mutant (Supp. Fig. S2A).

We expressed this construct under control of the $d y f-7$ promoter, which is expressed in sensory neurons, and examined embryos at the time of dendrite extension. We found that the DYF $-7^{\text {ecto }}$ and DYF $-7^{\text {cyt }}$ fragments localized differently, consistent with proteolytic cleavage at the CFCS (Fig. 2B). Deletion of the CFCS led to increased colocalization, confirming that DYF- 
7 undergoes CFCS-dependent proteolysis in vivo (Supp. Fig. S2B). The membrane-anchored cytoplasmic tail of DYF-7 localized diffusely across the neuronal membrane with enrichment at dendrite endings (Fig. 2B, red), consistent with our previous observations (Heiman and Shaham, 2009). In contrast, the ZP domain of DYF- $7^{\text {ecto }}$ localized with exquisite precision to caps at dendrite endings (Fig. 2B, green). This localization requires the ZP domain, as a construct lacking the ZP domain localized diffusely throughout the extra-embryonic space (Supp. Fig. $\mathrm{S} 2 \mathrm{C})$.

Multiple dendrite caps were observed, corresponding to the amphid and other sense organs in the head (Fig. 2C). In some cases, these structures took the shape of short linear segments, consistent with the luminal surface of a tube (Fig. 2C, arrow). Immunostaining with an antibody against AJM-1 revealed that each of these caps is situated adjacent to a tight junction (Fig. 2D). The position of these caps thus corresponds to the outward-facing apical surfaces of the dendrites.

Next, we asked where DYF-7 would localize if it were misexpressed in other epithelia. We expressed the tagged DYF- $7^{\text {ecto }}$ construct under control of gut-specific or ubiquitously-expressed promoters. In the gut, DYF- $7^{\text {ecto }}$ localized to the lumen, which is the apical surface of this wellstudied model epithelium (Leung et al., 1999) (Fig. 2E). When expressed ubiquitously, DYF$7^{\text {ecto }}$ localized to the lumens of the gut and pharynx as well as to dendritic caps at the developing nose (Fig. 2F). It was absent from non-epithelial regions of the embryo. Immunostaining against AJM-1 confirmed that misexpressed DYF- $7^{\text {ecto }}$ localizes in the pharynx and gut specifically to apical surfaces (Fig. 2G).

DYF-7 forms fibrils in vivo and in vitro. Other ZP domain proteins contribute to apical ECM by polymerizing into fibrils that form a meshwork at the apical surfaces of epithelia (Jovine et 
al., 2002; Jovine et al., 2004; Jovine et al., 2006; Schaeffer et al., 2009). We therefore asked whether DYF-7 also forms fibrils.

Previous EM studies noted the appearance of extracellular fibrils in the developing amphid (Oikonomou et al., 2011). However, these structures are difficult to visualize using standard approaches because their appearance depends on the angle of sectioning and the developmental stage of the embryo. We used a method called positional correlative anatomy EM to provide greater control over these variables (Kolotuev, 2014; Burel et al., 2018). Briefly, a high-pressure frozen sample is flat-embedded at the surface of a resin block, a region of interest is identified at high magnification, and the sample is then oriented for ultramicrotome sectioning with respect to known anatomical features.

Using this method, we identified embryos undergoing dendrite extension — between the comma and 1.5-fold stages of embryogenesis ( $~ 420$ min post-fertilization) — and sectioned them at an angle parallel to the long axis of the dendrites (Fig. 3A, top). In wild-type animals at this stage, cilia had not yet formed but a centriole/basal body was always present at the dendrite endings (annotated in Fig. 3Aiii, arrowheads). We found that the developing dendrites form direct contacts on each other, rather than making individual junctions to the sheath as in the mature structure. The dendrites are bundled together in a single channel of the sheath glial cell that is continuous with the channel of the socket glial cell, which in turn is open to the extraembryonic space (Fig. 3A). In all cases, we observed fibrils that originate near the dendrite endings, extend through the sheath:socket channel, and terminate near the extra-embryonic ECM, extending $\sim 1.5 \mu \mathrm{m}$ in total (Fig. 3A; fibrils, brackets). These fibrils were consistently visible across serial sections in all embryos imaged ( $\mathrm{n}=3$ amphids).

Next, we compared this to $d y f-7$ mutant embryos at the same stage. In $d y f-7$ embryos at this stage, the nascent dendrites and sheath have just begun to withdraw from the developing nose (Fig. 3B, top). The dendrites are organized within the sheath in a manner similar to wild type but 
the sheath forms a closed cavity rather than an open channel (Fig. 3Bvii-ix). We did not observe fibrils in any of the $d y f-7$ embryos imaged ( $\mathrm{n}=6$ amphids). We considered the possibility that fibrils might be present but disorganized and hard to recognize (e.g., too short, or oriented randomly). However, we were unable to identify fibril-like structures in any serial sections across a variety of embryo orientations and a range of section thicknesses (60-100nm). This finding suggests that DYF-7 is required for formation of these fibrils.

Finally, we asked whether DYF-7 is sufficient to form fibrils in vitro. We expressed sfGFPDYF-7 in Drosophila S2 cells. We observed GFP-positive clumps and tangles extending from the surfaces of cells (Fig. 3C). In some cases, GFP-positive fibrils appeared to wrap around the cells (Fig. 3Cii, iii). Thus, our results indicate that DYF-7 is sufficient to form fibrils in vitro, and that it is necessary for the formation or maintenance of such fibrils at the apical surface of the developing amphid in vivo. These observations support the idea that, like ZP domain proteins in other systems, DYF-7 is an apical ECM component.

DYF-7 is required to prevent rupture of the tube-shaped glial pore. Studies in C. elegans and Drosophila have shown that disrupting ZP domain proteins that are part of the apical ECM leads to epithelial rupture, including loss of a continuous lumen in the narrow epithelial tubes of the $C$. elegans excretory system and the Drosophila tracheal system (Wilkin et al., 2000; Jaźwińska et al., 2003; Bökel et al., 2005; Kelley et al., 2015; Gill et al., 2016). Previously, we focused on the role of DYF-7 in anchoring dendrites to the embryonic nose, however, viewing DYF-7 as an apical ECM component, we decided to ask if dendrite anchoring defects might be related to rupture of the tube-shaped glial pore that normally surrounds the dendrites.

In $d y f-7$ mutants, amphid dendrites and the sheath glial cell fail to extend but the socket glial cell still extends a process to the nose (Heiman and Shaham, 2009) (Fig. 4A). First, we examined tight junctions and apical-basal markers in the socket. At the nose, tight junctions 
were still present between the socket and the skin, and the apical marker ApiGreen still localized to the outward-facing surface (Fig. 4B,C). However, the auto-junction that normally seals the socket into a tube was absent and no signs of the normal socket channel could be seen. In 32 of 48 amphids, the sheath and socket appeared completely dissociated from each other; however, in the remaining 16 amphids, the socket glial cell extended an ectopic posterior process to contact the shortened sheath glial cell (see schematic in Fig. 4A). In these examples, tight junction markers colocalized at the sheath:socket contact, but appeared as a small dot rather than a ring as in wild type (Fig. 4D). ApiGreen did not localize to the sheath:socket contact (Fig. 4E). These results suggest that the socket cell retains tight junctions and apical-basal polarity, but no longer forms a continuous channel with the sheath.

Next, we examined these markers in the amphid sheath and an amphid neuron. Both cells retained their tight junctions and apical-basal polarity (Fig. 4F-H). The dendrite still appeared to enter the sheath and form tight junctions with it, consistent with our previous EM analysis (Heiman and Shaham, 2009) (Fig. 4F). However, the apical surface of the sheath glial cell appeared to be organized in a network of cyst-like internal pouches rather than an open channel (Fig. 4H). These defects are reminiscent of the loss of lumen integrity caused by disruption of ZP domain proteins in other narrow epithelial tubes.

Together, these results strongly suggest that amphid neurons and glia use a developmental mechanism that shares key features with other epithelia, namely, the use of a fibril-forming ZP domain protein in the apical ECM to prevent rupture of a narrow epithelial tube.

\section{DYF-7 defects are enhanced by loss of FRM-2, a homolog of epithelial integrity proteins}

Next, we wanted to identify additional factors that help to promote morphogenesis of amphid neurons and glia. We reasoned that, if the amphid shares developmental features with epithelia, then it might use additional factors that are typically found in developing epithelia, such as 
proteins involved in apical-basal polarity or cell junction integrity. Conversely, if the amphid differs in important ways from conventional epithelia, then it might rely more heavily on factors that are typically associated with neuronal or glial development, or novel factors.

To this end, we performed an unbiased genetic screen using a sensitized background in which DYF-7 activity is mildly impaired. We took advantage of a hypomorphic missense allele, $d y f-7(n s 117)$, in which only $\sim 35 \%$ of amphids are affected (Heiman and Shaham, 2009). Briefly, we performed chemical mutagenesis of $d y f-7(n s 117)$ mutants bearing a fluorescent marker for a single amphid neuron. 1000 F2 self-progeny bearing novel unique homozygous mutations were picked to individual plates and their clonal F3 offspring were visually screened for increased (enhanced) penetrance of the dendrite extension defect (Fig. 5A). We isolated two mutants with heritably increased penetrance: $h m n 162$ and hmn169. As hmn169 was less strongly enhanced and exhibited semi-dominance (see Methods), we chose to focus on hmn162.

Single-step mapping and sequencing of hmnl62 identified a nonsense mutation in a previously uncharacterized gene called frm-2 (Fig. 5B). Mutants bearing frm-2(hmn162) alone exhibit very rare $(1 \pm 1 \%)$ dendrite defects (Fig. 5C). However, whereas $d y f-7(n s 117)$ exhibits $35 \pm 5 \%$ penetrant dendrite defects, the $d y f-7(n s 117) ;$ frm-2(hmn162) double mutant exhibits an enhanced penetrance of $70 \pm 4 \%$ (Fig. 5C). A wild-type frm-2 genomic fragment expressed under its own regulatory sequences completely rescues this phenotype, returning the penetrance to the

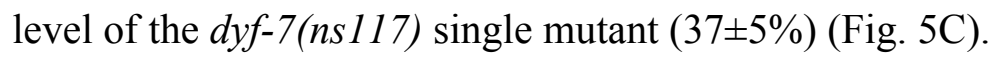

frm-2 is predicted to encode a FERM-domain protein most closely related to mammalian EPB41L5, zebrafish mosaic eyes (moe), and Drosophila Yurt (Yrt) (Fig. 5B). Each of these proteins has been shown to interact with the Crumbs apical polarity complex to regulate epithelial morphogenesis (Hsu et al., 2006; Laprise et al., 2006; Gosens et al., 2007; Laprise et al., 2009; Salis et al., 2017). Disruption of EPB41L5, moe, and Yrt has been shown in each of these systems to cause disorganized tight junctions and loss of epithelial integrity (Jensen and 
Westerfield, 2004; Salis et al., 2017; Schell et al., 2017). Interestingly, in Drosophila trachea, the relationship between Yrt and apical ECM has been examined, and these pathways were found to act independently and in parallel to shape epithelial tubes, an observation that would be consistent with the loss of FRM-2 enhancing $d y f-7$ defects (Laprise et al., 2010).

To determine whether FRM-2 might be acting directly in the amphid, we examined its expression. At the time of dendrite extension, a frm-2pro:GFP reporter is expressed brightly in the developing epithelium of the pharynx and gut, with much weaker but consistent expression in sensory neurons (Fig. 5D, arrowheads). We examined FRM-2 protein localization using a frm2pro:FRM-2-GFP reporter. We consistently observed localization at amphid dendrite endings (Fig. 5E, arrow), although it was sometimes obscured by the much brighter signal from the pharynx and gut.

These results support the idea that FRM-2 acts apically in the developing amphid to prevent epithelial rupture, similar to what has been shown for EPB41L5, moe, and Yrt in other epithelia. Our results are consistent with the idea that, like Yrt, FRM-2 acts in parallel to apical ECM proteins like DYF-7 to regulate the formation of a narrow epithelial tube. While our unbiased screen was not comprehensive, it is interesting that it identified a factor that most closely resembles ones found in other epithelia, rather than ones typically involved in the development of neurons or glia.

\section{Other environmentally-exposed neurons also require DYF-7}

In addition to the amphid, other sensory neurons in the head are exposed directly to the environment and are thus likely to have epithelial properties (Ward et al., 1975). These include the cephalic (CEP), inner labial (IL), and outer labial (OL) neurons. Each of these classes of neuron has its own dedicated glia (CEP sheath and socket; IL sheath and socket; OL sheath and socket) that form a tube-shaped channel around the dendrites. In all cases, there are junctions 
between the dendrites and sheath; the sheath and socket; and the socket and skin to delineate an outward-facing surface (Ward et al., 1975). We wondered if these neurons also require DYF-7.

To test this idea, we used cell-specific promoters to visualize amphid, CEP, OL, and IL dendrites in wild-type and $d y f-7$ animals (Fig. 6). In $d y f-7$ mutants, amphid neurons are typically $\sim 10 \%$ of wild-type length (Fig. $6 \mathrm{~B}, \mathrm{C}$ ). We found that CEP, OL, and IL neurons are also affected by the loss of DYF-7 (Fig. 6B,C). The defects were highly penetrant, with $>90 \%$ of dendrites having lengths at least five standard deviations below the wild-type mean (Fig. 6C). These dendrites were typically $\sim 80 \%$ of wild-type length (Fig. $6 \mathrm{C}$ ), but length varied even within a class; for example, ventral CEPs were consistently more affected than dorsal CEPs $(75.2 \pm 17.4$ and $91.2 \pm 3.2$ percent of nose length, respectively).

For comparison, we also examined the URY sensory neuron. This neuron extends an unbranched dendrite to the nose that associates with sheath glia, but its dendrite ending does not enter the glial channel and is not exposed to the environment; thus, it is not expected to have epithelial properties (Ward et al., 1975). We found that these dendrites were mostly unaffected by loss of DYF-7, suggesting that its role is specific to environmentally-exposed neurons (Fig. 6B,C).

Together, these results indicate that the amphid, CEP, OL, and IL neurons share a dependence on DYF-7. Thus, what we have learned about epithelial features of amphid neurons and glia might apply broadly to other environmentally-exposed neurons in C. elegans and, perhaps, in other organisms as well. 


\section{DISCUSSION}

\section{Epithelial properties of amphid neurons and glia}

Our results suggest that amphid neurons and glia exhibit features of an epithelium, including tight junctions and apical-basal polarity. Similar anatomical arrangements are found in the olfactory and vomeronasal systems of mammals and are the predominant type of sensory structure in invertebrates, including the campaniform, trichoid, and chordotonal neurons of Drosophila and most sensory neurons of C. elegans (IL, OL, CEP in the head as discussed above, as well as phasmids, deirids and male-specific tail sensory neurons) (White et al., 1986; Hartenstein, 1988). Thus, neurons with epithelial properties may be an ancestral type of sensory structure.

Viewed as an epithelium, the glial pore of the amphid especially resembles narrow epithelial tubes found in capillaries and the branching ductwork of kidney, pancreas, lung, or other organs (Sundaram and Cohen, 2017). The development of narrow epithelial tubes has been studied extensively in the C. elegans excretory system, which includes three tube-forming cells: the canal, duct, and pore cells (Sundaram and Buechner, 2016). The canal and pore cells bear anatomical similarities to the amphid sheath and socket, respectively, with the canal and sheath forming seamless tubes that are not lined with cuticle, and the pore and socket using autojunctions to create cuticle-lined tubes that are open to the environment via junctions with the skin. An additional curious parallel is that the excretory pore and amphid socket can each act as stem cells, dividing post-embryonically to give rise to neurons (Sulston and Horvitz, 1977; Sammut et al., 2015). Besides their anatomical similarities, the excretory system and amphid share genetic and molecular features: Several mutants have been described that cause strong phenotypes affecting both the excretory system and amphid (Rdy phenotype, for "rod-like larval lethality and dye-filling defective"), and several molecular markers exhibit prominent expression shared by both these organs (e.g., pros-1, daf-6, lin-48, grl-2) (Michaux et al., 2000; Johnson et 
al., 2001; Perens and Shaham, 2005; Hao et al., 2006b; Liégeois et al., 2007; Kolotuev et al., 2013; Kage-Nakadai et al., 2016; Wallace et al., 2016).

These parallels are consistent with the idea that the development of the amphid resembles that of other narrow epithelial tubes. With its easily visualized morphology and the ability to label or genetically manipulate each neuron and glial cell with single-cell specificity, the amphid offers a novel and potentially powerful model system with which to ask questions about epithelial development. The epithelial properties of amphid neurons also raise new questions, including (1) how can a cell simultaneously have apical-basal and axon-dendrite polarity?; (2) given that the transcription factor LIN-26 is thought to promote epithelial fates while repressing neuronal fates(Labouesse et al., 1994; Labouesse et al., 1996), what kind of transcriptional programs allow the simultaneous expression of epithelial and neuronal genes?; and (3) why do DYF-7 and FRM-2 affect epithelia that contain neurons and glia more strongly than they affect other epithelia?

\section{DYF-7 as an apical ECM component}

ZP domain proteins are found in the apical ECM of nearly all epithelia and are present from cnidaria to chordates (Plaza et al., 2010; Matveev et al., 2012). They play important roles in human disease: the tectorins of the inner ear are mutated in deafness; the tumor suppressor DMBT1 is expressed in many epithelia and is frequently mutated in cancer; uromodulin in the kidney is mutated in hereditary nephropathy; GP-2 is expressed in the pancreas and intestine and acts as an autoantigen in Crohn's disease; and the TGF- $\beta$ co-receptor endoglin is expressed in endothelia and is mutated in vascular dysplasia and elevated in pre-eclampsia (Legan et al., 1997; Ligtenberg et al., 2007; Gregory et al., 2014; Roggenbuck et al., 2014; Devuyst et al., 2017). Previously, it was unclear how the expression of DYF-7 in neurons fit with this wellestablished literature on ZP domain proteins in the apical ECM of epithelia. Our results clarify 
that, like other ZP domain proteins, DYF-7 localizes to apical surfaces and polymerizes into fibrils, and thus it is likely to be an apical ECM component as well.

\section{Morphogenesis of neurons and glia within an epithelium}

Our results suggest a model in which epithelial properties of amphid neurons and glia play an integral role in their morphogenesis. First, amphid neurons and glia form an apical-basal polarized rosette shortly after the cells are born (Fan et al., 2018). Next, this rosette interacts with the developing epithelium of the skin and is carried to the nose (Fan et al., 2018). Finally, the cell bodies migrate away while their apical surfaces and cell junctions remain anchored at the nose (Heiman and Shaham, 2009). This anchoring requires apical ECM including DYF-7 and contributions from apically-localized FRM-2. In the absence of these factors, the developing tube-shaped glial pore ruptures at glial junctions and, although each of the individual cells retains its apical-basal polarity, the continuous lumen from sheath to socket is lost. These defects are comparable to phenotypes seen in the C. elegans excretory system or Drosophila tracheal tubes upon disruption of apical ECM (Jaźwińska et al., 2003; Wang et al., 2006; Stone et al., 2009; Mancuso et al., 2012; Gill et al., 2016; Forman-Rubinsky et al., 2017; Pu et al., 2017; Rosa et al., 2018). Thus, amphid dendrites are shaped by interactions within an epithelium composed of neurons, glia, and skin.

These features seem to be shared with other epithelial sense organs in C. elegans (CEP, $\mathrm{IL}$, and OL). Intriguingly, retrograde extension has recently been reported in developing olfactory neurons in vertebrates. In zebrafish, olfactory placodes (which will give rise to olfactory epithelia) develop adjacent to the surface of the brain (Breau et al., 2017). Olfactory placode neurons attach nascent axons near the brain surface and then the cell bodies move away, extending axons behind them (Breau et al., 2017). The mechanism of anchoring in this case has not been described. However, given that much of our nervous system develops as a 
bioRxiv preprint doi: https://doi.org/10.1101/393850; this version posted August 16, 2018. The copyright holder for this preprint (which was not certified by peer review) is the author/funder, who has granted bioRxiv a license to display the preprint in perpetuity. It is made available under Low et al.

neuroepithelium - including sensory placodes, the cortex, and the cerebellum - it will be interesting to explore whether neuron-epithelial interactions might also help to shape dendrites and axons in other contexts. 


\section{METHODS}

\section{Strains and Plasmids}

Strains were constructed in the N2 background and cultured under standard conditions (Brenner, 1974; Stiernagle, 2006). Strains, transgenes, and plasmids are listed in Supp. Tables S1-S3 respectively. All strains and plasmids are available upon request.

\section{Fluorescence microscopy and image processing}

Animals were mounted on 2\% agarose pads in water or M9 buffer (Sulston et al., 1983) with 0$50 \mathrm{mM}$ sodium azide depending on developmental stage, and imaged using a Deltavision Core imaging system (Applied Precision) with UApo/340 40x 1.35NA, PlanApo 60x 1.42NA, and UPlanApo 100x 1.4NA objectives (Olympus) and CoolSnap HQ2 camera. The amphid socket promoter (grl-2pro) yields bright expression in the excretory system that obscures the amphid features we wished to highlight in Fig. 4 and Supp. Fig. S1; we therefore used a fluorescence stereomicroscope to select rare mosaic animals that lacked excretory system expression to obtain the amphid images in these figures. Images were deconvolved using Softworx (Applied Precision) and maximum-brightness projections were obtained from contiguous optical sections using ImageJ. All projections used the same upper and lower limits across wavelengths, however, a thinner optical stack was often used in high-magnification images shown as insets. Due to large differences in signal intensity between neuronal and glial cell bodies and their thin processes, gamma settings were adjusted for the red signal in S1C in order to show the relevant structures clearly.

\section{Immunofluorescence}

Embryos were fixed using a methanol-acetone procedure and stained with anti-AJM-1 primary antibody MH27 (Francis and Waterston, 1991) obtained from Developmental Studies 
Hybridoma Bank established at the University of Iowa by the NICHD/NIH) and sheep antimouse DyLight649 secondary antibody (Jackson ImmunoResearch). Briefly, embryos were cracked by sandwiching them between a coverslip and Superfrost Plus slide (Fisher), then freezing them 5 min on a metal block on dry ice, and briskly removing the coverslip. The slide was placed in methanol at $-20^{\circ} \mathrm{C}$ for $20 \mathrm{~min}$ followed by acetone at $-20^{\circ} \mathrm{C}$ for $10 \mathrm{~min}$, then washed in PBST (phosphate buffered saline with $0.1 \%$ Tween) and incubated in blocking solution (0.5\% I-Block (ThermoFisher) in PBST) at room temperature for $1 \mathrm{~h}$. Primary and secondary antibodies were used at 1:10 and 1:100 respectively in blocking solution. GFP fluorescence was preserved and visualized directly.

\section{Electron microscopy}

Samples were subjected to high pressure freezing followed by freeze-substitution as described previously (Kolotuev et al., 2010). Samples were flat embedded, targeted and sectioned using the positional correlation and tight trimming approach (Kolotuev, 2014). This method facilitates identification of rare features in complex samples by using a precisely targeted region for sectioning. The sample was first viewed on a high-magnification optical microscope (Leica SPE confocal, 63x Leica oil immersion objective) and the distance between the first section and the expected location of the feature of interest was calculated. The sample was next mounted for ultramicrotome sectioning, and advancement of the sectioning was tracked following the feed count parameters of the ultramicrotome. $100 \mathrm{~nm}$ sections were collected on the slot-formvar coated grids and observed with respect to the desired position using a JEOL JEM 1400 TEM microscope (JEOL, Japan). 


\section{S2 cells}

Drosophila Schneider (S2) cells (Invitrogen) were cultured and transfected with FuGene HD

(Roche) as described previously (Heiman and Shaham, 2009). Two days after transfection, cells and medium were harvested, applied in a small volume $(\sim 10 \mu 1)$ directly to a coverslip without a slide, and imaged as described above.

\section{Genetic screen and mutant identification}

Fourth larval stage (L4) animals of strain CHB99 (oyIs44 V; $d y f-7(n s$ 117) X) were mutagenized using $70 \mathrm{mM}$ ethyl methanesulfonate (EMS, Sigma) at $20^{\circ} \mathrm{C}$ for $4 \mathrm{~h}$. Nonclonal F2 progeny were picked to 1000 individual plates. F3 populations were scored visually using a fluorescence stereomicroscope for increased (enhanced) or decreased (suppressed) penetrance of dendrite extension defects. Isolates corresponding to hmn162 and $h m n 169$ exhibited $87 \%$ and $61 \%$ penetrance, respectively $(\mathrm{n}=100)$. Following a backcross to $d y f-7(n s 117) \mathrm{kyIs} 136$ [str-2pro:GFP] $X$ males, cross-progeny exhibited $37 \%$ and $55 \%$ penetrance, respectively $(n>150)$, suggesting a recessive mode of inheritance for hmn162 and a dominant or partially dominant mode of inheritance for hmn169. In both cases, penetrance was similar between hermaphrodite and male cross-progeny, suggesting an absence of sex linkage. For mapping, 160 backcrossed F2 animals were picked to individual plates and the resulting F3 progeny were screened for enhanced penentrance of dendrite defects. 40 plates of animals with enhanced penetrance were identified, and these recombinants were pooled and subjected to genomic DNA extraction and wholegenome sequencing for one-step mapping (Doitsidou et al., 2010). The parental strains were also sequenced. Analysis with CloudMap (Minevich et al., 2012) identified a linked region on LG III including a nonsense mutation in frm-2 (AAGTTTGTT[C>T]AGTGCAAGG). 
bioRxiv preprint doi: https://doi.org/10.1101/393850; this version posted August 16, 2018. The copyright holder for this preprint (which was not certified by peer review) is the author/funder, who has granted bioRxiv a license to display the preprint in perpetuity. It is made available under Low et al.

\section{Dendrite length measurements}

L4 animals were mounted and imaged as described above, and dendrite lengths were measured using the segmented line tool in ImageJ. The dendrite was traced from the point where it joins the cell body to the point where it ends at the nose, then normalized by the distance from the cell body to the nose to account for variance in the size of the animal. 
bioRxiv preprint doi: https://doi.org/10.1101/393850; this version posted August 16, 2018. The copyright holder for this preprint (which was not

certified by peer review) is the author/funder, who has granted bioRxiv a license to display the preprint in perpetuity. It is made available under

Low et al.

\section{ACKNOWLEDGMENTS}

We thank Shai Shaham, under whose support and guidance this project was initiated; Agnes

Burel and Marie Therese Lavault for assistance with electron microscopy; Elizabeth Lamkin and

Karolina Mizeracka for plasmids; Jeff Simske and Verena Göbel for advice on AJM-1 and ERM-

1 markers; Elisabeth Altendorfer and Monica Colaiacovo for assistance with

immunofluorescence; Meera Sundaram, Zhirong Bao, and Li Fan for sharing unpublished data

and generous advice; members of the Heiman lab for comments on the manuscript; and the $C$.

elegans Genome Center and WormBase. This work was supported by an NSF Graduate

Research Fellowship (IGM), March of Dimes Basil O'Connor Starter Scholar Award (MGH), and NIH R01GM108754 (MGH). 


\section{REFERENCES}

Bacaj, T., Tevlin, M., Lu, Y. and Shaham, S. (2008). Glia are essential for sensory organ function in C. elegans. Science 322, 744-747.

Bargmann, C. I. (2006). Chemosensation in C. elegans. WormBook 1-29.

Blacque, O. E. and Sanders, A. A. (2014). Compartments within a compartment: what C. elegans can tell us about ciliary subdomain composition, biogenesis, function, and disease. Organogenesis 10, 126-137.

Bökel, C., Prokop, A. and Brown, N. H. (2005). Papillote and Piopio: Drosophila ZP-domain proteins required for cell adhesion to the apical extracellular matrix and microtubule organization. J Cell Sci 118, 633-642.

Bokhove, M. and Jovine, L. (2018). Structure of Zona Pellucida Module Proteins. Curr Top Dev Biol 130, 413-442.

Breau, M. A., Bonnet, I., Stoufflet, J., Xie, J., De Castro, S. and Schneider-Maunoury, S. (2017). Extrinsic mechanical forces mediate retrograde axon extension in a developing neuronal circuit. Nat Commun 8, 282.

Brenner, S. (1974). The genetics of Caenorhabditis elegans. Genetics 77, 71-94.

Burel, A., Lavault, M. T., Chevalier, C., Gnaegi, H., Prigent, S., Mucciolo, A., Dutertre, S., Humbel, B. M., Guillaudeux, T. and Kolotuev, I. (2018). A targeted 3D EM and correlative microscopy method using SEM array tomography. Development $\mathbf{1 4 5}$,

Celestrin, K., Díaz-Balzac, C. A., Tang, L. T. H., Ackley, B. D. and Bülow, H. E. (2018). Four specific immunoglobulin domains in UNC-52/Perlecan function with NID-1/Nidogen during dendrite morphogenesis in. Development 145,

Devuyst, O., Olinger, E. and Rampoldi, L. (2017). Uromodulin: from physiology to rare and complex kidney disorders. Nat Rev Nephrol 13, 525-544.

Díaz-Balzac, C. A., Rahman, M., Lázaro-Peña, M. I., Martin Hernandez, L. A., Salzberg, Y., Aguirre-Chen, C., Kaprielian, Z. and Bülow, H. E. (2016). Muscle- and SkinDerived Cues Jointly Orchestrate Patterning of Somatosensory Dendrites. Curr Biol 26, 2379-2387.

Doitsidou, M., Poole, R. J., Sarin, S., Bigelow, H. and Hobert, O. (2010). C. elegans mutant identification with a one-step whole-genome-sequencing and SNP mapping strategy. PLoS One 5, e15435.

Dong, X., Liu, O. W., Howell, A. S. and Shen, K. (2013). An extracellular adhesion molecule complex patterns dendritic branching and morphogenesis. Cell 155, 296-307.

Fan, L., Kovacevic, I., Heiman, M. and Bao, Z. (2018). A multicellular rosette-mediated collective dendrite extension. bioRxiv

Firestein, S. (2001). How the olfactory system makes sense of scents. Nature 413, 211-218.

Forman-Rubinsky, R., Cohen, J. D. and Sundaram, M. V. (2017). Lipocalins Are Required for Apical Extracellular Matrix Organization and Remodeling in. Genetics 207, 625-642.

Francis, R. and Waterston, R. H. (1991). Muscle cell attachment in Caenorhabditis elegans. $J$ Cell Biol 114, 465-479.

Frank, M. M. and Goodrich, L. V. (2018). Talking back: Development of the olivocochlear efferent system. Wiley Interdiscip Rev Dev Biol e324.

Garcia-Gonzalo, F. R. and Reiter, J. F. (2017). Open Sesame: How Transition Fibers and the Transition Zone Control Ciliary Composition. Cold Spring Harb Perspect Biol $\mathbf{9}$,

Gill, H. K., Cohen, J. D., Ayala-Figueroa, J., Forman-Rubinsky, R., Poggioli, C., Bickard, K., Parry, J. M., Pu, P., Hall, D. H. and Sundaram, M. V. (2016). Integrity of Narrow Epithelial Tubes in the C. elegans Excretory System Requires a Transient Luminal Matrix. PLoS Genet 12, e1006205.

Gilleland, C. L., Falls, A. T., Noraky, J., Heiman, M. G. and Yanik, M. F. (2015). Computer- 
Assisted Transgenesis of Caenorhabditis elegans for Deep Phenotyping. Genetics 201, 3946.

Gosens, I., Sessa, A., den Hollander, A. I., Letteboer, S. J., Belloni, V., Arends, M. L., Le Bivic, A., Cremers, F. P., Broccoli, V. and Roepman, R. (2007). FERM protein EPB41L5 is a novel member of the mammalian CRB-MPP5 polarity complex. Exp Cell Res 313, 3959-3970.

Graziadei, P. P. and Graziadei, G. A. (1979). Neurogenesis and neuron regeneration in the olfactory system of mammals. I. Morphological aspects of differentiation and structural organization of the olfactory sensory neurons. J Neurocytol 8, 1-18.

Gregory, A. L., Xu, G., Sotov, V. and Letarte, M. (2014). Review: the enigmatic role of endoglin in the placenta. Placenta 35 Suppl, S93-9.

Han, C., Wang, D., Soba, P., Zhu, S., Lin, X., Jan, L. Y. and Jan, Y. N. (2012). Integrins regulate repulsion-mediated dendritic patterning of drosophila sensory neurons by restricting dendrites in a 2D space. Neuron 73, 64-78.

Hao, L., Johnsen, R., Lauter, G., Baillie, D. and Bürglin, T. R. (2006a). Comprehensive analysis of gene expression patterns of hedgehog-related genes. BMC Genomics 7, 280.

Hao, L., Johnsen, R., Lauter, G., Baillie, D. and Bürglin, T. R. (2006b). Comprehensive analysis of gene expression patterns of hedgehog-related genes. BMC Genomics 7, 280.

Hartenstein, V. (1988). Development of Drosophila larval sensory organs: spatiotemporal pattern of sensory neurones, peripheral axonal pathways and sensilla differentiation. Development 102, 869-886.

Heiman, M. G. and Shaham, S. (2009). DEX-1 and DYF-7 establish sensory dendrite length by anchoring dendritic tips during cell migration. Cell 137, 344-355.

Hsu, Y. C., Willoughby, J. J., Christensen, A. K. and Jensen, A. M. (2006). Mosaic Eyes is a novel component of the Crumbs complex and negatively regulates photoreceptor apical size. Development 133, 4849-4859.

Jaźwińska, A., Ribeiro, C. and Affolter, M. (2003). Epithelial tube morphogenesis during Drosophila tracheal development requires Piopio, a luminal ZP protein. Nat Cell Biol 5, 895-901.

Jensen, A. M. and Westerfield, M. (2004). Zebrafish mosaic eyes is a novel FERM protein required for retinal lamination and retinal pigmented epithelial tight junction formation. Curr Biol 14, 711-717.

Jiang, N., Soba, P., Parker, E., Kim, C. C. and Parrish, J. Z. (2014). The microRNA bantam regulates a developmental transition in epithelial cells that restricts sensory dendrite growth. Development 141, 2657-2668.

Johnson, A. D., Fitzsimmons, D., Hagman, J. and Chamberlin, H. M. (2001). EGL-38 Pax regulates the ovo-related gene lin-48 during Caenorhabditis elegans organ development. Development 128, 2857-2865.

Jovine, L., Janssen, W. G., Litscher, E. S. and Wassarman, P. M. (2006). The PLAC1homology region of the ZP domain is sufficient for protein polymerisation. BMC Biochem 7, 11.

Jovine, L., Qi, H., Williams, Z., Litscher, E. and Wassarman, P. M. (2002). The ZP domain is a conserved module for polymerization of extracellular proteins. Nat Cell Biol 4, 457461.

Jovine, L., Qi, H., Williams, Z., Litscher, E. S. and Wassarman, P. M. (2004). A duplicated motif controls assembly of zona pellucida domain proteins. Proc Natl Acad Sci US A 101, 5922-5927.

Kage-Nakadai, E., Ohta, A., Ujisawa, T., Sun, S., Nishikawa, Y., Kuhara, A. and Mitani, S. (2016). Caenorhabditis elegans homologue of Prox1/Prospero is expressed in the glia and is required for sensory behavior and cold tolerance. Genes Cells 21, 936-948. 
Kelley, M., Yochem, J., Krieg, M., Calixto, A., Heiman, M. G., Kuzmanov, A., Meli, V., Chalfie, M., Goodman, M. B., Shaham, S. et al. (2015). FBN-1, a fibrillin-related protein, is required for resistance of the epidermis to mechanical deformation during $\mathrm{C}$. elegans embryogenesis. Elife 4,

Kim, K. and Li, C. (2004). Expression and regulation of an FMRFamide-related neuropeptide gene family in Caenorhabditis elegans. J Comp Neurol 475, 540-550.

Kim, M. E., Shrestha, B. R., Blazeski, R., Mason, C. A. and Grueber, W. B. (2012). Integrins establish dendrite-substrate relationships that promote dendritic self-avoidance and patterning in drosophila sensory neurons. Neuron 73, 79-91.

Kolotuev, I. (2014). Positional correlative anatomy of invertebrate model organisms increases efficiency of TEM data production. Microsc Microanal 20, 1392-1403.

Kolotuev, I., Hyenne, V., Schwab, Y., Rodriguez, D. and Labouesse, M. (2013). A pathway for unicellular tube extension depending on the lymphatic vessel determinant Prox1 and on osmoregulation. Nat Cell Biol 15, 157-168.

Kolotuev, I., Schwab, Y. and Labouesse, M. (2010). A precise and rapid mapping protocol for correlative light and electron microscopy of small invertebrate organisms. Biol Cell 102, 121-132.

Köppen, M., Simske, J. S., Sims, P. A., Firestein, B. L., Hall, D. H., Radice, A. D., Rongo, C. and Hardin, J. D. (2001). Cooperative regulation of AJM-1 controls junctional integrity in Caenorhabditis elegans epithelia. Nat Cell Biol 3, 983-991.

L'Etoile, N. D. and Bargmann, C. I. (2000). Olfaction and odor discrimination are mediated by the C. elegans guanylyl cyclase ODR-1. Neuron 25, 575-586.

Labouesse, M., Hartwieg, E. and Horvitz, H. R. (1996). The Caenorhabditis elegans LIN-26 protein is required to specify and/or maintain all non-neuronal ectodermal cell fates.

Development 122, 2579-2588.

Labouesse, M., Sookhareea, S. and Horvitz, H. R. (1994). The Caenorhabditis elegans gene lin-26 is required to specify the fates of hypodermal cells and encodes a presumptive zincfinger transcription factor. Development 120, 2359-2368.

Laprise, P., Beronja, S., Silva-Gagliardi, N. F., Pellikka, M., Jensen, A. M., McGlade, C. J. and Tepass, U. (2006). The FERM protein Yurt is a negative regulatory component of the Crumbs complex that controls epithelial polarity and apical membrane size. Dev Cell 11, 363-374.

Laprise, P., Lau, K. M., Harris, K. P., Silva-Gagliardi, N. F., Paul, S. M., Beronja, S., Beitel, G. J., McGlade, C. J. and Tepass, U. (2009). Yurt, Coracle, Neurexin IV and the $\mathrm{Na}(+), \mathrm{K}(+)$-ATPase form a novel group of epithelial polarity proteins. Nature 459, 1141 1145.

Laprise, P., Paul, S. M., Boulanger, J., Robbins, R. M., Beitel, G. J. and Tepass, U. (2010). Epithelial polarity proteins regulate Drosophila tracheal tube size in parallel to the luminal matrix pathway. Curr Biol 20, 55-61.

Legan, P. K., Rau, A., Keen, J. N. and Richardson, G. P. (1997). The mouse tectorins. Modular matrix proteins of the inner ear homologous to components of the sperm-egg adhesion system. J Biol Chem 272, 8791-8801.

Leung, B., Hermann, G. J. and Priess, J. R. (1999). Organogenesis of the Caenorhabditis elegans intestine. Dev Biol 216, 114-134.

Liang, X., Dong, X., Moerman, D. G., Shen, K. and Wang, X. (2015). Sarcomeres Pattern Proprioceptive Sensory Dendritic Endings through UNC-52/Perlecan in C. elegans. Dev Cell 33, 388-400.

Liégeois, S., Benedetto, A., Michaux, G., Belliard, G. and Labouesse, M. (2007). Genes required for osmoregulation and apical secretion in Caenorhabditis elegans. Genetics $\mathbf{1 7 5}$, 709-724. 
Ligtenberg, A. J., Veerman, E. C., Nieuw Amerongen, A. V. and Mollenhauer, J. (2007). Salivary agglutinin/glycoprotein-340/DMBT1: a single molecule with variable composition and with different functions in infection, inflammation and cancer. Biol Chem 388, 12751289.

Liu, X., Wang, X. and Shen, K. (2016). Receptor tyrosine phosphatase CLR-1 acts in skin cells to promote sensory dendrite outgrowth. Dev Biol 413, 60-69.

Lockwood, C. A., Lynch, A. M. and Hardin, J. (2008). Dynamic analysis identifies novel roles for DLG-1 subdomains in AJM-1 recruitment and LET-413-dependent apical focusing. $J$ Cell Sci 121, 1477-1487.

Maduro, M. and Pilgrim, D. (1995). Identification and cloning of unc-119, a gene expressed in the Caenorhabditis elegans nervous system. Genetics 141, 977-988.

Mancuso, V. P., Parry, J. M., Storer, L., Poggioli, C., Nguyen, K. C., Hall, D. H. and Sundaram, M. V. (2012). Extracellular leucine-rich repeat proteins are required to organize the apical extracellular matrix and maintain epithelial junction integrity in C. elegans. Development 139, 979-990.

Matveev, I. V., Adonin, L. S., Shaposhnikova, T. G. and Podgornaya, O. I. (2012). Aurelia aurita-Cnidarian with a prominent medusiod stage. J Exp Zool B Mol Dev Evol 318, 1-12.

McLachlan, I. G. and Heiman, M. G. (2013). Shaping dendrites with machinery borrowed from epithelia. Curr Opin Neurobiol 23, 1005-1010.

Mello, C. C., Kramer, J. M., Stinchcomb, D. and Ambros, V. (1991). Efficient gene transfer in C.elegans: extrachromosomal maintenance and integration of transforming sequences. EMBO J 10, 3959-3970.

Michaux, G., Gansmuller, A., Hindelang, C. and Labouesse, M. (2000). CHE-14, a protein with a sterol-sensing domain, is required for apical sorting in C. elegans ectodermal epithelial cells. Curr Biol 10, 1098-1107.

Minevich, G., Park, D. S., Blankenberg, D., Poole, R. J. and Hobert, O. (2012). CloudMap: a cloud-based pipeline for analysis of mutant genome sequences. Genetics 192, 1249-1269.

Nechipurenko, I. V., Olivier-Mason, A., Kazatskaya, A., Kennedy, J., McLachlan, I. G., Heiman, M. G., Blacque, O. E. and Sengupta, P. (2016). A Conserved Role for Girdin in Basal Body Positioning and Ciliogenesis. Dev Cell 38, 493-506.

Nguyen, P. A., Liou, W., Hall, D. H. and Leroux, M. R. (2014). Ciliopathy proteins establish a bipartite signaling compartment in a C. elegans thermosensory neuron. J Cell Sci 127, 5317-5330.

Oikonomou, G., Perens, E. A., Lu, Y. and Shaham, S. (2012). Some, but not all, retromer components promote morphogenesis of C. elegans sensory compartments. Dev Biol 362, 42-49.

Oikonomou, G., Perens, E. A., Lu, Y., Watanabe, S., Jorgensen, E. M. and Shaham, S. (2011). Opposing activities of LIT-1/NLK and DAF-6/patched-related direct sensory compartment morphogenesis in C. elegans. PLoS Biol 9, e1001121.

Parrish, J. Z., Xu, P., Kim, C. C., Jan, L. Y. and Jan, Y. N. (2009). The microRNA bantam functions in epithelial cells to regulate scaling growth of dendrite arbors in drosophila sensory neurons. Neuron 63, 788-802.

Peden, E. M. and Barr, M. M. (2005). The KLP-6 kinesin is required for male mating behaviors and polycystin localization in Caenorhabditis elegans. Curr Biol 15, 394-404.

Perens, E. A. and Shaham, S. (2005). C. elegans daf-6 encodes a patched-related protein required for lumen formation. Dev Cell 8, 893-906.

Perkins, L. A., Hedgecock, E. M., Thomson, J. N. and Culotti, J. G. (1986). Mutant sensory cilia in the nematode Caenorhabditis elegans. Dev Biol 117, 456-487.

Plaza, S., Chanut-Delalande, H., Fernandes, I., Wassarman, P. M. and Payre, F. (2010). From A to Z: apical structures and zona pellucida-domain proteins. Trends Cell Biol 20, 
524-532.

Procko, C., Lu, Y. and Shaham, S. (2011). Glia delimit shape changes of sensory neuron receptive endings in C. elegans. Development 138, 1371-1381.

Pu, P., Stone, C. E., Burdick, J. T., Murray, J. I. and Sundaram, M. V. (2017). The Lipocalin LPR-1 Cooperates with LIN-3/EGF Signaling To Maintain Narrow Tube Integrity in. Genetics 205, 1247-1260.

Roggenbuck, D., Reinhold, D., Schierack, P., Bogdanos, D. P., Conrad, K. and Laass, M. W. (2014). Crohn's disease specific pancreatic antibodies: clinical and pathophysiological challenges. Clin Chem Lab Med 52, 483-494.

Roper, S. D. (2013). Taste buds as peripheral chemosensory processors. Semin Cell Dev Biol 24, 71-79.

Rosa, J. B., Metzstein, M. M. and Ghabrial, A. S. (2018). An Ichor-dependent apical extracellular matrix regulates seamless tube shape and integrity. PLoS Genet 14, e1007146.

Salis, P., Payre, F., Valenti, P., Bazellieres, E., Le Bivic, A. and Mottola, G. (2017). Crumbs, Moesin and Yurt regulate junctional stability and dynamics for a proper morphogenesis of the Drosophila pupal wing epithelium. Sci Rep 7, 16778.

Sammut, M., Cook, S. J., Nguyen, K. C. Q., Felton, T., Hall, D. H., Emmons, S. W., Poole, R. J. and Barrios, A. (2015). Glia-derived neurons are required for sex-specific learning in C. elegans. Nature 526, 385-390.

Sasakura, H., Inada, H., Kuhara, A., Fusaoka, E., Takemoto, D., Takeuchi, K. and Mori, I. (2005). Maintenance of neuronal positions in organized ganglia by SAX-7, a

Caenorhabditis elegans homologue of L1. EMBO J 24, 1477-1488.

Schaeffer, C., Santambrogio, S., Perucca, S., Casari, G. and Rampoldi, L. (2009). Analysis of uromodulin polymerization provides new insights into the mechanisms regulating ZP domain-mediated protein assembly. Mol Biol Cell 20, 589-599.

Schell, C., Rogg, M., Suhm, M., Helmstädter, M., Sellung, D., Yasuda-Yamahara, M., Kretz, O., Küttner, V., Suleiman, H., Kollipara, L. et al. (2017). The FERM protein EPB41L5 regulates actomyosin contractility and focal adhesion formation to maintain the kidney filtration barrier. Proc Natl Acad Sci U S A 114, E4621-E4630.

Singhvi, A., Liu, B., Friedman, C. J., Fong, J., Lu, Y., Huang, X. Y. and Shaham, S. (2016). A Glial K/Cl Transporter Controls Neuronal Receptive Ending Shape by Chloride Inhibition of an rGC. Cell 165, 936-948.

Steinke, A., Meier-Stiegen, S., Drenckhahn, D. and Asan, E. (2008). Molecular composition of tight and adherens junctions in the rat olfactory epithelium and fila. Histochem Cell Biol 130, 339-361.

Stiernagle, T. (2006). Maintenance of C. elegans. WormBook 1-11.

Stone, C. E., Hall, D. H. and Sundaram, M. V. (2009). Lipocalin signaling controls unicellular tube development in the Caenorhabditis elegans excretory system. Dev Biol 329, 201-211.

Sulston, J. E. and Horvitz, H. R. (1977). Post-embryonic cell lineages of the nematode, Caenorhabditis elegans. Dev Biol 56, 110-156.

Sulston, J. E., Schierenberg, E., White, J. G. and Thomson, J. N. (1983). The embryonic cell lineage of the nematode Caenorhabditis elegans. Dev Biol 100, 64-119.

Sundaram, M. V. and Buechner, M. (2016). The Caenorhabditis elegans Excretory System: A Model for Tubulogenesis, Cell Fate Specification, and Plasticity. Genetics 203, 35-63.

Sundaram, M. V. and Cohen, J. D. (2017). Time to make the doughnuts: Building and shaping seamless tubes. Semin Cell Dev Biol 67, 123-131.

Tenenbaum, C. M., Misra, M., Alizzi, R. A. and Gavis, E. R. (2017). Enclosure of Dendrites by Epidermal Cells Restricts Branching and Permits Coordinated Development of Spatially Overlapping Sensory Neurons. Cell Rep 20, 3043-3056.

Tobin, D. M., Madsen, D. M., Kahn-Kirby, A., Peckol, E. L., Moulder, G., Barstead, R., 
Maricq, A. V. and Bargmann, C. I. (2002). Combinatorial expression of TRPV channel proteins defines their sensory functions and subcellular localization in $\mathrm{C}$. elegans neurons. Neuron 35, 307-318.

Tsalik, E. L., Niacaris, T., Wenick, A. S., Pau, K., Avery, L. and Hobert, O. (2003). LIM homeobox gene-dependent expression of biogenic amine receptors in restricted regions of the C. elegans nervous system. Dev Biol 263, 81-102.

Wallace, S. W., Singhvi, A., Liang, Y., Lu, Y. and Shaham, S. (2016). PROS-1/Prospero Is a Major Regulator of the Glia-Specific Secretome Controlling Sensory-Neuron Shape and Function in C. elegans. Cell Rep 15, 550-562.

Wang, F., Julien, D. P. and Sagasti, A. (2013). Journey to the skin: Somatosensory peripheral axon guidance and morphogenesis. Cell Adh Migr 7, 388-394.

Wang, S., Jayaram, S. A., Hemphälä, J., Senti, K. A., Tsarouhas, V., Jin, H. and Samakovlis, C. (2006). Septate-junction-dependent luminal deposition of chitin deacetylases restricts tube elongation in the Drosophila trachea. Curr Biol 16, 180-185.

Wang, W., Perens, E. A., Oikonomou, G., Wallace, S. W., Lu, Y. and Shaham, S. (2017). IGDB-2, an Ig/FNIII protein, binds the ion channel LGC-34 and controls sensory compartment morphogenesis in C. elegans. Dev Biol 430, 105-112.

Wang, Y., Apicella, A., Lee, S. K., Ezcurra, M., Slone, R. D., Goldmit, M., Schafer, W. R., Shaham, S., Driscoll, M. and Bianchi, L. (2008). A glial DEG/ENaC channel functions with neuronal channel DEG-1 to mediate specific sensory functions in C. elegans. EMBOJ 27, 2388-2399.

Ward, S., Thomson, N., White, J. G. and Brenner, S. (1975). Electron microscopical reconstruction of the anterior sensory anatomy of the nematode Caenorhabditis elegans. $J$ Comp Neurol 160, 313-337.

White, J. G., Southgate, E., Thomson, J. N. and Brenner, S. (1986). The structure of the nervous system of the nematode Caenorhabditis elegans. Philos Trans $R$ Soc Lond B Biol Sci 314, 1-340.

Wilkin, M. B., Becker, M. N., Mulvey, D., Phan, I., Chao, A., Cooper, K., Chung, H. J., Campbell, I. D., Baron, M. and MacIntyre, R. (2000). Drosophila dumpy is a gigantic extracellular protein required to maintain tension at epidermal-cuticle attachment sites. Curr Biol 10, 559-567.

Yu, S., Avery, L., Baude, E. and Garbers, D. L. (1997). Guanylyl cyclase expression in specific sensory neurons: a new family of chemosensory receptors. Proc Natl Acad Sci US A 94, 3384-3387.

Zhu, T., Liang, X., Wang, X. M. and Shen, K. (2017). Dynein and EFF-1 control dendrite morphology by regulating the localization pattern of SAX-7 in epidermal cells. J Cell Sci 130, 4063-4071.

Zimmerman, A., Bai, L. and Ginty, D. D. (2014). The gentle touch receptors of mammalian skin. Science 346, 950-954.

Zou, W., Shen, A., Dong, X., Tugizova, M., Xiang, Y. K. and Shen, K. (2016). A multiprotein receptor-ligand complex underlies combinatorial dendrite guidance choices in. Elife 5 , 

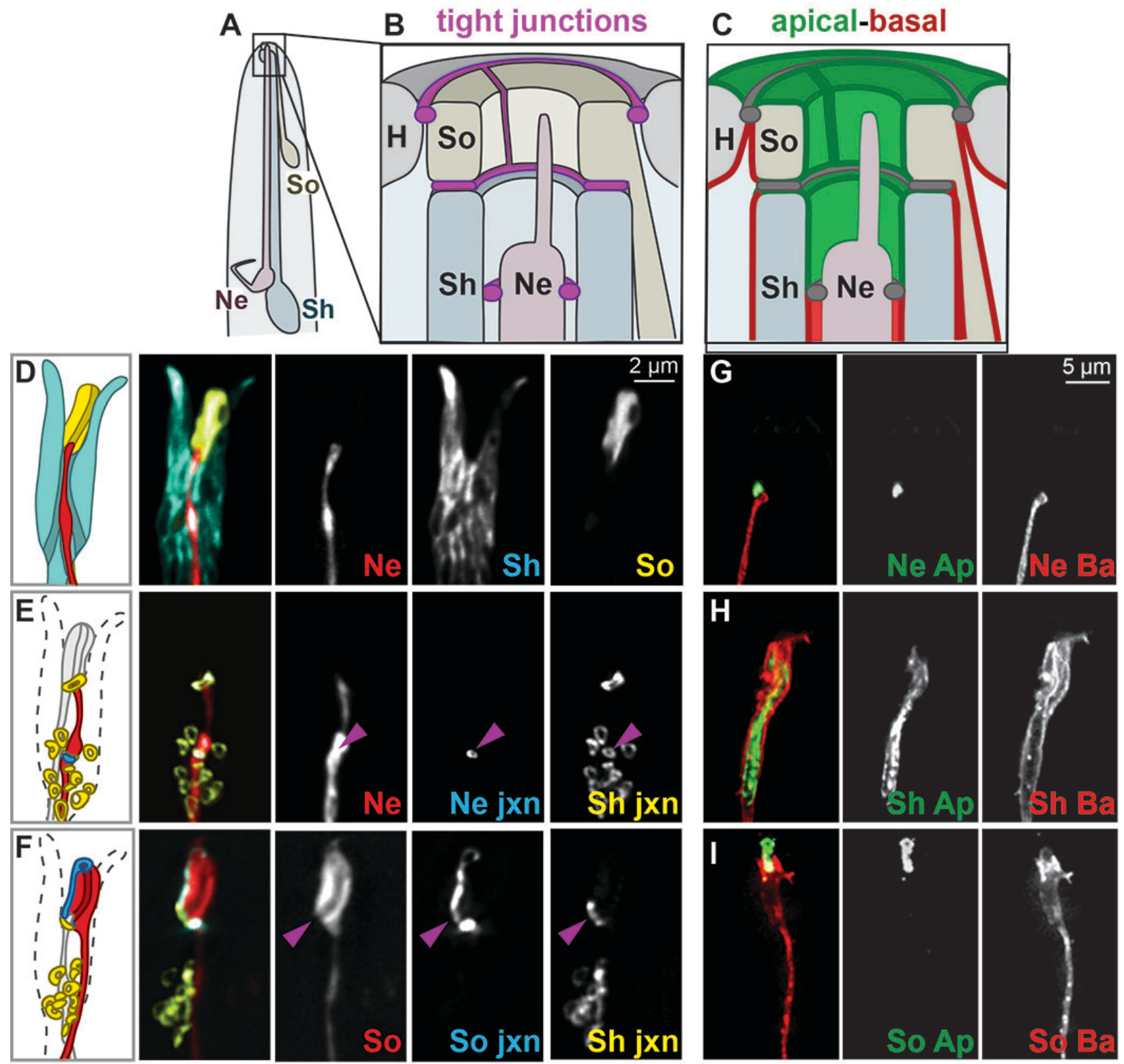

Figure 1. Amphid neurons and glia exhibit tight junctions and distinct apical and

\section{basolateral surfaces.}

(A-C) Schematics showing relative positions of (A) amphid dendrite endings, (B) tight junctions (purple), and (C) apical (green) and basolateral (red) surfaces. For simplicity, only a single neuron is drawn. (D) Cell-specific markers were used to visualize single neurons and glia. ASER neuron (gcy-5pro, red); sheath glia (F16F9.3pro, blue); socket glia (grl-2pro, yellow). (E,F) Overlap of neuron:sheath and sheath:socket tight junctions was visualized by using these promoters to express AJM-1-YFP in the sheath and cytoplasmic mCherry plus AJM-1-CFP in 
bioRxiv preprint doi: https://doi.org/10.1101/393850; this version posted August 16, 2018. The copyright holder for this preprint (which was not certified by peer review) is the author/funder, who has granted bioRxiv a license to display the preprint in perpetuity. It is made available under Low et al.

(E) the neuron or (F) the socket. Dotted line in schematics, approximate outline of sheath; purple arrowheads, position of overlapping tight junctions. (G-I) The apical and basolateral markers ApiGreen (Ap, green) and BasoRed (Ba, red) (see Methods and Supp. Fig. S1D) were expressed in $(\mathrm{G})$ the neuron, $(\mathrm{H})$ the sheath, $(\mathrm{I})$ the socket using the same promoters. Ne, neuron; Sh, sheath glia; So, socket glia; H, hypodermis (skin); jxn, junction; Ap, ApiGreen; Ba, BasoRed. 

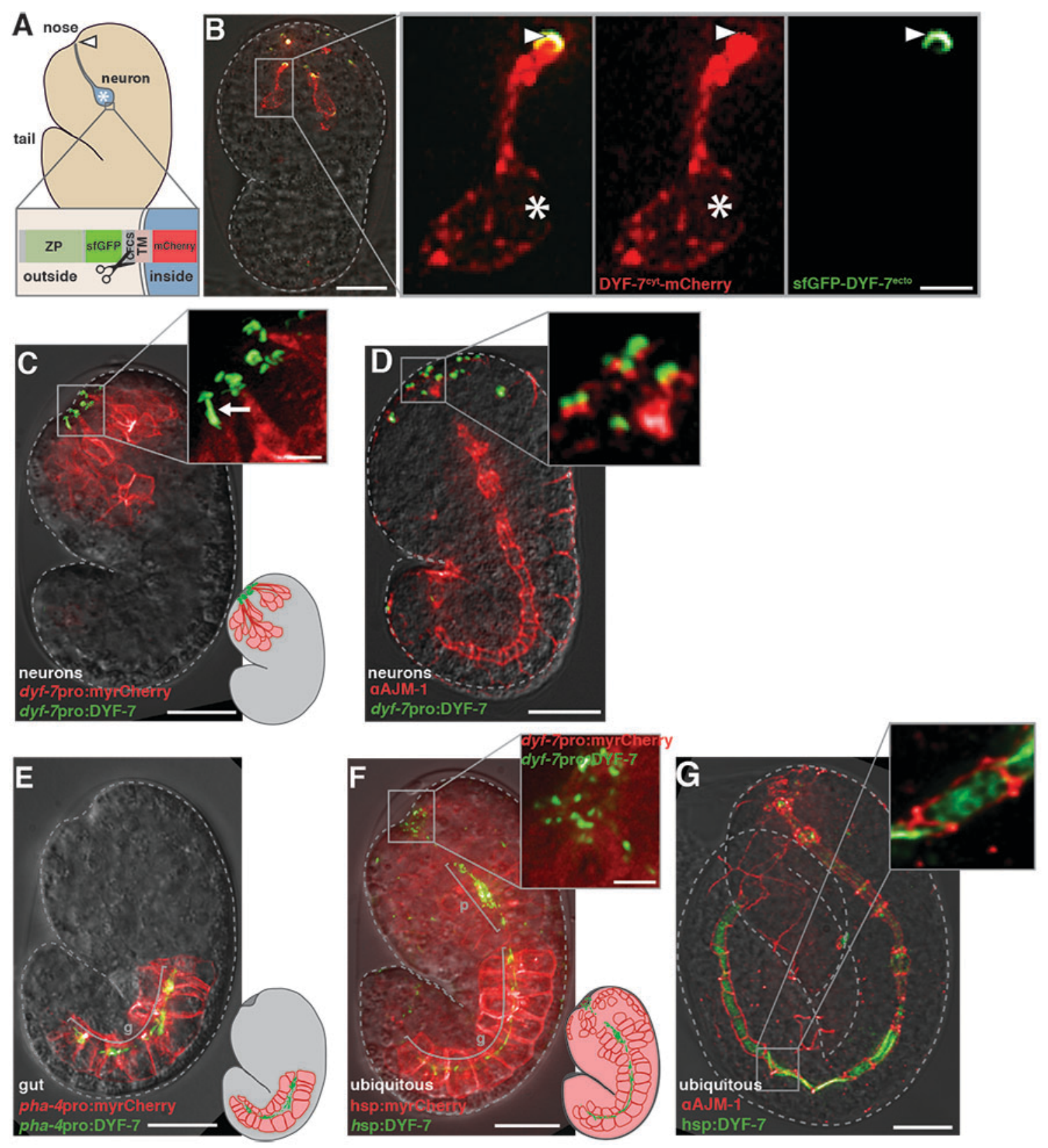

Figure 2. DYF-7 is cleaved in vivo and its ectodomain localizes to apical surfaces.

(A) Cartoon schematic of an embryo showing a single neuron (blue; cell body, *) with its dendrite extending to the developing nose (dendrite ending, arrowhead). Topology of the DYF-7 reporter construct, consisting of the ZP domain (ZP), superfolder GFP tag (sfGFP), consensus furin-family cleavage site (CFCS), transmembrane segment (TM), and cytoplasmic region tagged with mCherry (mCherry). (B) A live, intact embryo expressing this construct in sensory neurons ( $d y f-7$ pro) during dendrite extension. (C,D) Embryos expressing sfGFP-DYF-7 in 
bioRxiv preprint doi: https://doi.org/10.1101/393850; this version posted August 16, 2018. The copyright holder for this preprint (which was not certified by peer review) is the author/funder, who has granted bioRxiv a license to display the preprint in perpetuity. It is made available under Low et al.

sensory neurons (dyf-7pro) (C) with myristyl-mCherry or (D) with immunostaining against

AJM-1. Some structures appear as short linear segments (arrow) rather than rounded caps. (E-

G) Embryos misexpressing sfGFP-DYF-7 in (E) gut (pha-4pro) with myristyl-mCherry or (F,G)

ubiquitously (heat shock promoter) (F) with myristyl-mCherry or (G) with immunostaining

against AJM-1. Brackets mark pharynx (p) and gut (g). Scale bars: $10 \mu \mathrm{m}$, main panel; $2 \mu \mathrm{m}$, magnified insets. 

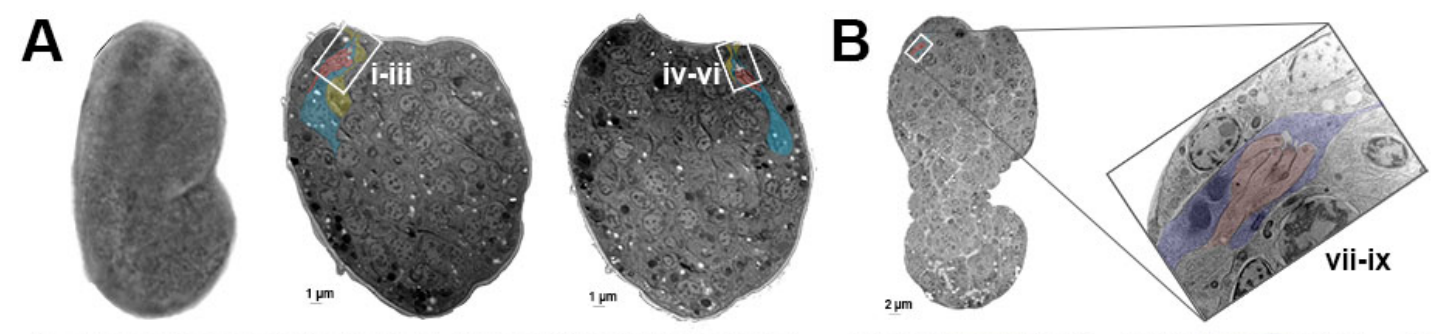

neuron
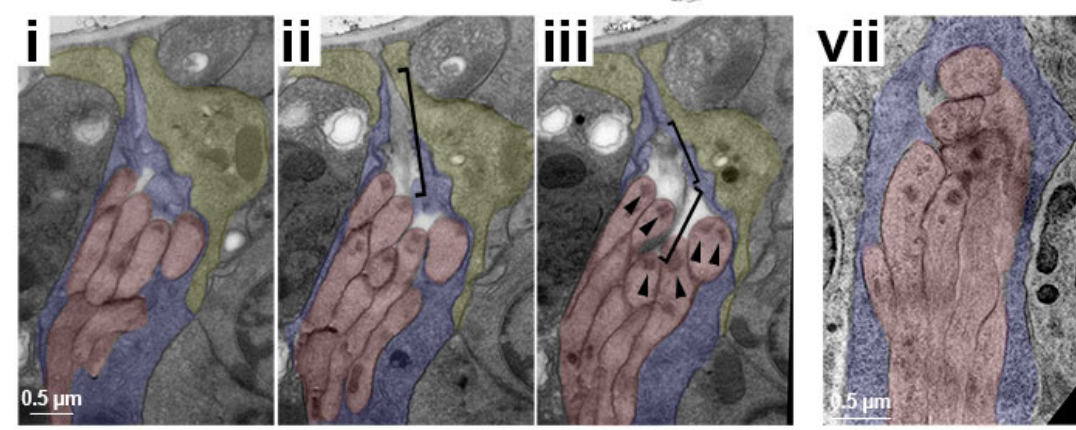

socket
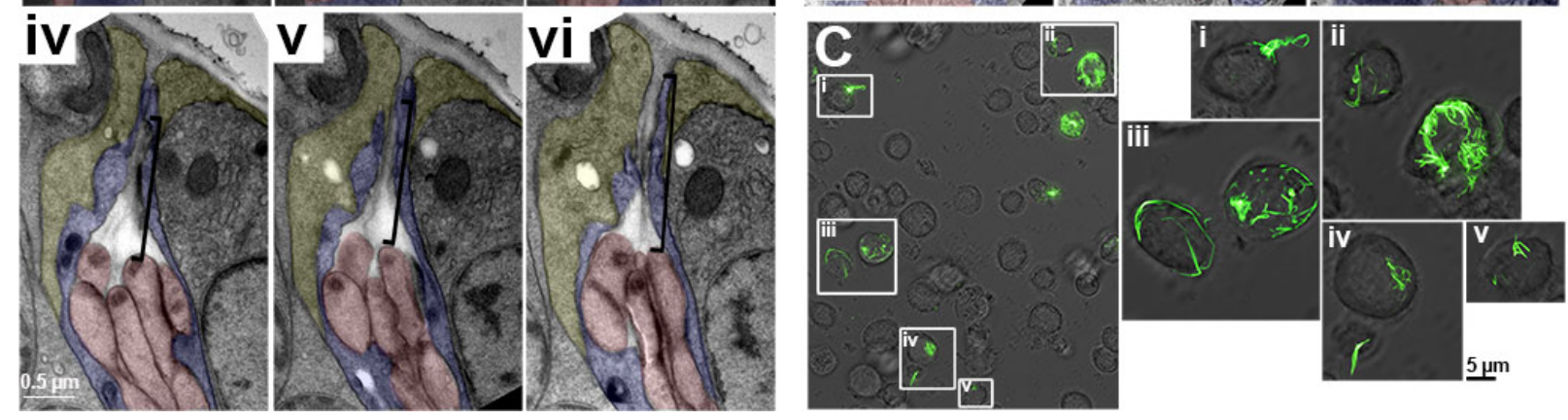

Figure 3. DYF-7 forms extracellular fibrils.

(A) Image of a wild-type embryo after high-pressure freezing, fixation, and flat embedding. Flat embedding allowed selection of embryos at the desired stage and orientation for sectioning.

Serial sectioning led to identification of the (i-iii) left- and (iv-vi) right-hand amphids. Three serial sections of each amphid are shown. Neurons, red; sheath, blue; socket, yellow. Basal bodies/centrioles are annotated in (iii) with arrowheads. Extracellular fibrils are marked with brackets. (B) Three serial sections (viii-ix) of an amphid in a $d y f-7$ embryo at the same developmental stage. The sheath forms a pocket around the neurons and no fibrils are visible. Basal bodies/centrioles appear normal (arrowheads). (C) Drosophila S2 cells were transfected with sfGFP-DYF-7. A representative field of cells is shown. GFP-labeled structures appeared as (i) a plume at the cell surface, (ii) complex tangles, (iii) puncta and fibrils that appear to encircle the cells, (iv, v) small webs. 


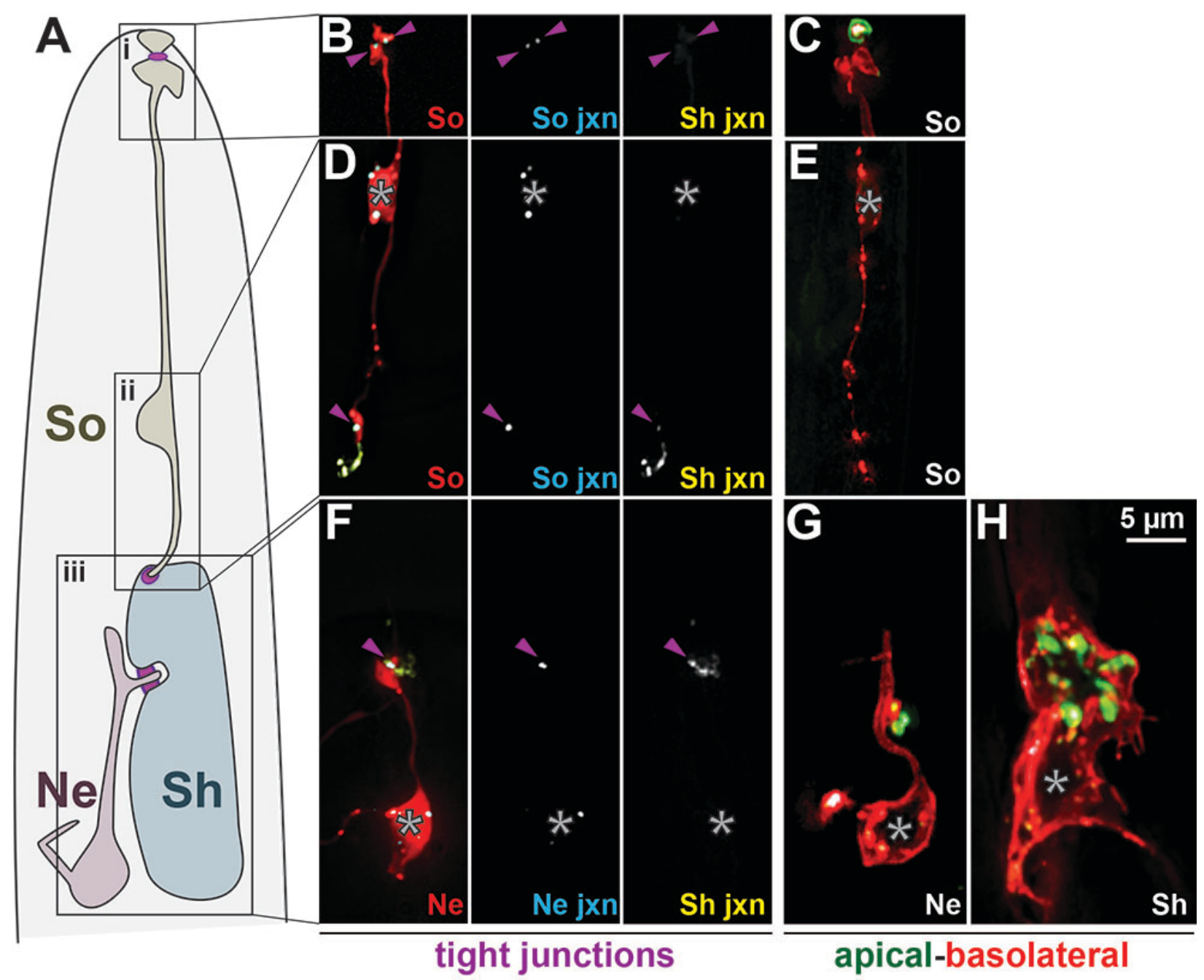

Figure 4. Disruption of the amphid glial channel in $d y f-7$ mutants

(A) Schematic showing the relative positions of the socket (So), sheath (Sh), and neurons (Ne) in a $d y f-7$ mutant. Posterior process from socket to sheath occurred in 16/48 amphids. Regions of interest are boxed: (i) socket:skin junction, shown in (B,C); (ii) sheath:socket junction, shown in (D,E); (iii) neuron:sheath junction, shown in (F-H). (B,D,F) AJM-1-YFP expressed in sheath plus cytoplasmic mCherry and AJM-1-CFP expressed in (B,D) socket or (F) neuron. (C,E,G,H) ApiGreen and BasoRed expressed in $(\mathrm{C}, \mathrm{E})$ socket, $(\mathrm{G})$ neuron, or $(\mathrm{H})$ sheath. All markers and promoters are the same as in Fig. 1. Purple arrowheads, positions of relevant tight junctions; asterisks, cell bodies. 


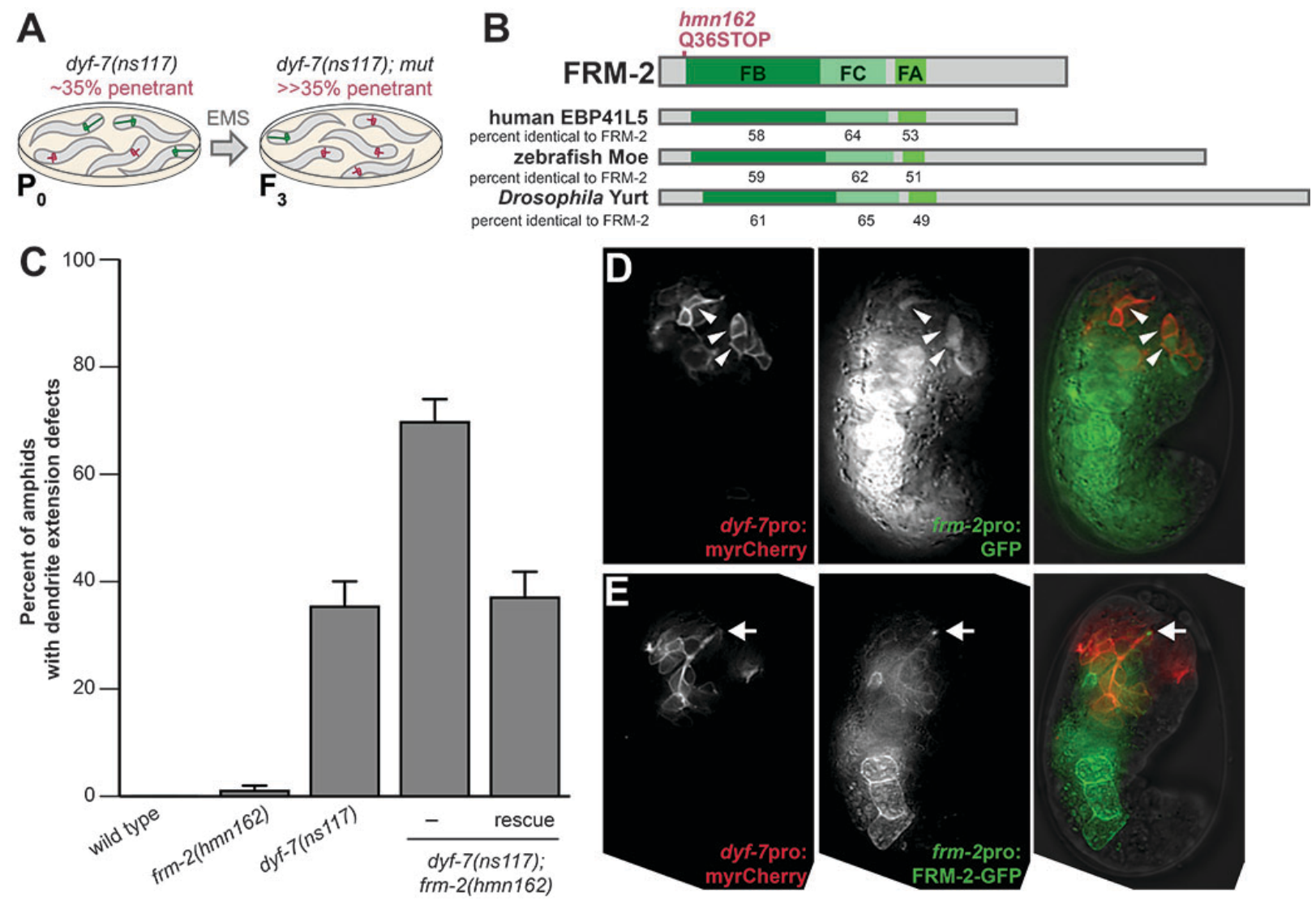

Figure 5. Loss of FRM-2 enhances weak $d y f-7$ defects

(A) Schematic of genetic strategy used to isolate enhancers of the hypomorphic missense mutant $d y f-7(n s 117)$. Parental (P0) strain exhibits $\sim 35 \%$ short amphids (red) and $\sim 65 \%$ full-length amphids (green). Following mutagenesis, clonal third generation (F3) progeny bearing additional mutations (mut) were visually screened for enhanced penetrance. (B) Schematic of the FRM-2 protein showing location of hmn 162 nonsense mutation. FRM-2 is roughly 50-60\% identical to human EPB41L5, zebrafish moe, and Drosophila Yurt throughout the FERM B-lobe (FB), FERM C-lobe (FC), and FERM-adjacent (FA) domains, with a more divergent carboxyterminal sequence. (C) frm-2(hmn162) enhances the amphid dendrite extension defects of $d y f$ 7(ns117). "rescue", animals bearing a transgene with a wild-type frm-2 genomic fragment. $\mathrm{n} \geq 100$ amphids per genotype. Error bars, standard error of the mean. (D) frm-2pro drives expression in sensory neurons ( $d y f-7$ pro, arrowheads) at the time of dendrite extension, as well as 
bioRxiv preprint doi: https://doi.org/10.1101/393850; this version posted August 16, 2018. The copyright holder for this preprint (which was not certified by peer review) is the author/funder, who has granted bioRxiv a license to display the preprint in perpetuity. It is made available under Low et al. aCC-BY-NC-ND 4.0 International license. Morphogenesis of epithelial neurons

bright expression in pharynx and gut. (E) A rescuing FRM-2-GFP construct expressed by its endogenous promoter localizes to developing dendrite endings (arrow). 


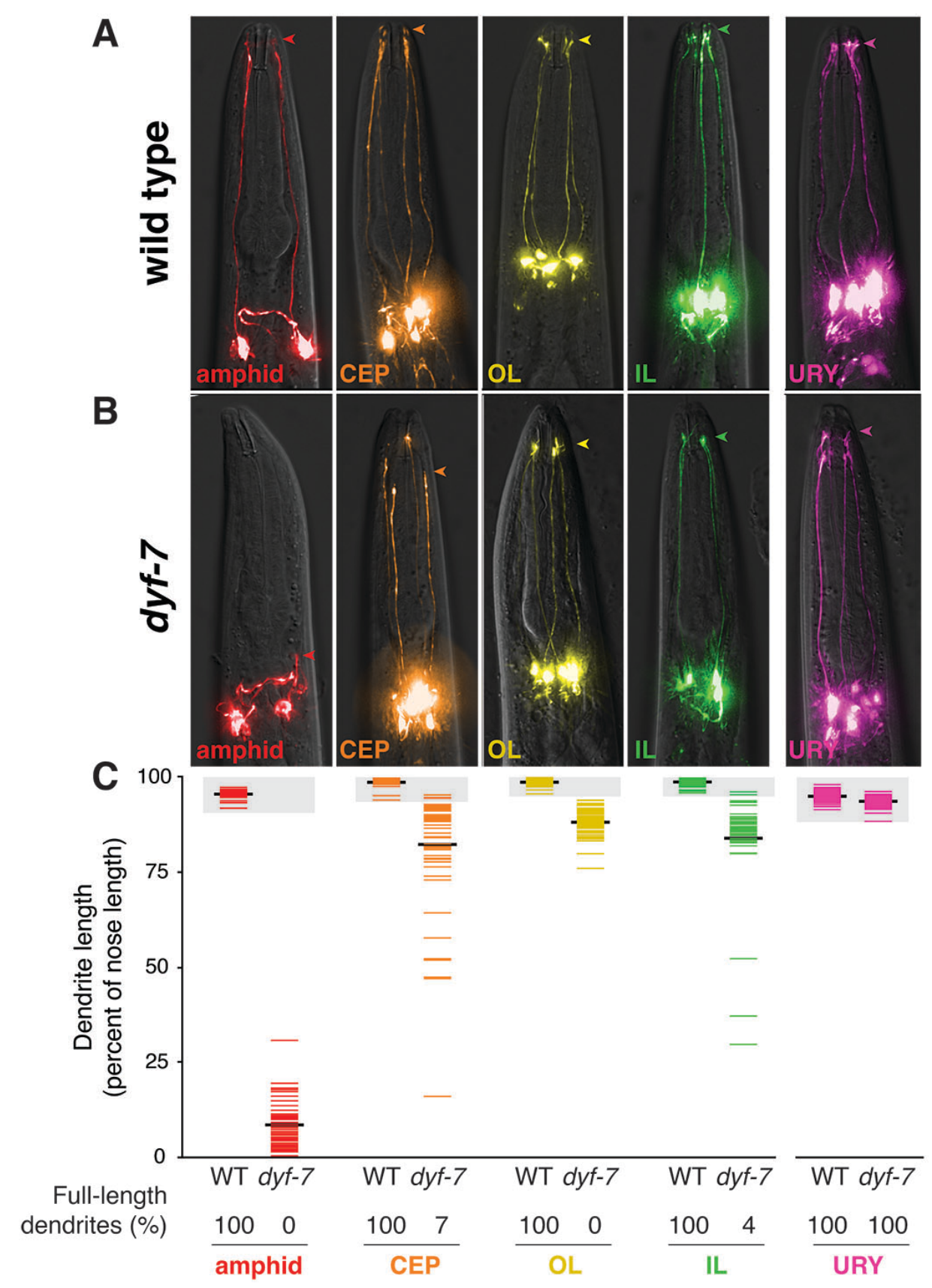

Figure 6. Sensory neurons within epithelia exhibit a shared dependence on DYF-7

Cell-specific markers were used to visualize sensory neurons within epithelia - amphid (AWC, odr-1pro), CEP (dat-1pro), OL (OLQ, ocr-4pro), and IL (IL2, klp-6pro) - as well as URY (tollpro), which is not within an epithelium, in (A) wild-type and (B) $d y f-7($ ns 119) null mutants. Arrowheads, position of dendrite endings. (C) Quantification of dendrite lengths as a fraction of nose length for each neuron in wild-type (left column) and $d y f-7$ (right column) animals. Colored bars represent individual dendrites ( $\mathrm{n} \geq 48$ per column); black bars represent means. Shaded areas 
bioRxiv preprint doi: https://doi.org/10.1101/393850; this version posted August 16, 2018. The copyright holder for this preprint (which was not certified by peer review) is the author/funder, who has granted bioRxiv a license to display the preprint in perpetuity. It is made available under Low et al. aCC-BY-NC-ND 4.0 International license. Morphogenesis of epithelial neurons

represent the wild-type mean \pm 5 standard deviations (SD) for each neuron type; the percent of dendrites in this range ("full-length dendrites") is given. 
bioRxiv preprint doi: https://doi.org/10.1101/393850; this version posted August 16, 2018. The copyright holder for this preprint (which was not certified by peer review) is the author/funder, who has granted bioRxiv a license to display the preprint in perpetuity. It is made available under Low et al.

\section{Supplemental Table S1. Strains used in this study}

\begin{tabular}{|c|c|c|}
\hline Strain & Genotype & Figure \\
\hline CHB1566 & hmnEx801 & $1 \mathrm{D}$ \\
\hline CHB1612 & hmnEx864 & $1 \mathrm{E}$ \\
\hline CHB1665 & hmnEx824 & $1 \mathrm{~F}$ \\
\hline CHB2721 & hmnEx 1535 & $1 G$ \\
\hline CHB2717 & hmnEx1533 & $1 \mathrm{H}$ \\
\hline CHB2719 & hmnEx1534 & $1 \mathrm{I}$ \\
\hline CHB440 & $d y f-7(n s 119) \mathrm{X} ;$ hmnEx149 & 2B \\
\hline CHB1939 & hmnEx1105 & $2 \mathrm{C}$ \\
\hline CHB436 & oyIs44 V; dyf-7(ns119) X; hmnEx145 & $2 \mathrm{D}$ \\
\hline CHB1530 & hmnEx799 & $2 \mathrm{E}$ \\
\hline CHB1557 & hmnEx821 & $2 \mathrm{~F}$ \\
\hline CHB558 & oyIs44 V; dyf-7(ns119) X; hmnEx216 & $2 \mathrm{G}$ \\
\hline CHB1 & wild type & $3 \mathrm{~A}$ \\
\hline CHB157 & $d y f-7(n s 119) \mathrm{X}$ & $3 \mathrm{~B}$ \\
\hline CHB1560 & $d y f-7(n s 119) \mathrm{X} ; \mathrm{hmnEx} 824$ & 4B,D \\
\hline CHB2718 & $d y f-7(n s 119) \mathrm{X} ; \mathrm{hmnEx} 1534$ & $4 \mathrm{C}, \mathrm{E}$ \\
\hline CHB1556 & $d y f-7(n s 119) \mathrm{X} ; \mathrm{hmnEx} 864$ & $4 \mathrm{~F}$ \\
\hline CHB2720 & $d y f-7(n s 119) \mathrm{X} ; \mathrm{hmnEx} 1535$ & $4 \mathrm{G}$ \\
\hline CHB2716 & $d y f-7(n s 119) \mathrm{X} ; \mathrm{hmn} \operatorname{Ex} 1533$ & $4 \mathrm{H}$ \\
\hline CHB1743 & oyIs $44 \mathrm{~V} ;$ hmnEx954 & $5 \mathrm{~A}$ \\
\hline CHB1741 & oyIs $44 \mathrm{~V} ;$ hmnEx953 & $5 \mathrm{~A}$ \\
\hline CHB1745 & oyIs $44 \mathrm{~V} ;$ hmnEx955 & $5 \mathrm{~A}$ \\
\hline CHB1739 & oyIs44 V; hmnEx952 & $5 \mathrm{~A}$ \\
\hline CHB1742 & oyIs44 V; dyf-7(ns119) X; hmnEx954 & $5 \mathrm{~B}$ \\
\hline CHB1740 & oyIs44 V; dyf-7(ns 119) X; hmnEx953 & $5 B$ \\
\hline CHB1744 & oyIs44 V; dyf-7(ns 119) X; hmnEx955 & $5 \mathrm{~B}$ \\
\hline CHB1738 & oyIs44 V; dyf-7(ns 119) X; hmnEx952 & $5 \mathrm{~B}$ \\
\hline CHB4 & oyIs $44 \mathrm{~V}$ & $5 \mathrm{C}$ \\
\hline CHB99 & oyIs44 V;dyf-7(ns117) X & $5 \mathrm{C}$ \\
\hline CHB1211 & frm-2(hmn162) III; oyIs44 V; $d y f-7(n s 117) \mathrm{X}$ & $5 \mathrm{C}$ \\
\hline CHB2750 & frm-2(hmn162) III; oyIs44 V; dyf-7(ns117) X; hmnEx1553 & $5 \mathrm{C}$ \\
\hline CHB2950 & hmnEx1667 & $5 \mathrm{D}$ \\
\hline CHB2951 & hmnEx1668 & $5 \mathrm{E}$ \\
\hline CHB1477 & hmnEx730 & S1A \\
\hline CHB1343 & hmnEx660 & S1B \\
\hline CHB1475 & hmnEx756 & $\mathrm{S} 1 \mathrm{C}$ \\
\hline CHB370 & oyIs44 V; dyf-7(ns 119) X; hmnEx97 & S2A \\
\hline CHB443 & oyIs44 V; dyf-7(ns119) X; hmnEx151 & S2A \\
\hline CHB436 & oyIs44 V; dyf-7(ns119) X; hmnEx145 & S2A \\
\hline CHB1613 & hmnEx865 & S2B \\
\hline CHB1615 & hmnEx867 & $\mathrm{S} 2 \mathrm{C}$ \\
\hline
\end{tabular}


bioRxiv preprint doi: https://doi.org/10.1101/393850; this version posted August 16,2018 . The copyright holder for this preprint (which was not certified by peer review) is the author/funder, who has granted bioRxiv a license to display the preprint in perpetuity. It is made available under Low et al.

\section{Supplemental Table S2. Transgenes used in this study}

A. Stably integrated transgenes

\begin{tabular}{|l|l|l|}
\hline Allele & Plasmids & Reference \\
\hline oyIs44 & odr-1pro:RFP, lin-15(+) & P. Sengupta, unpublished \\
\hline hmnIs27 & pCW11, pDP\#MM051 & this study \\
\hline
\end{tabular}

B. Unstable extrachromosomal transgenes

\begin{tabular}{|l|l|}
\hline Allele & Plasmids \\
\hline$h m n E x 97$ & pMH285, pRF4 \\
\hline$h m n E x 145$ & pCW11, pRF4 \\
\hline$h m n E x 149$ & pCW13, pRF4 \\
\hline$h m n E x 151$ & pCW12, pRF4 \\
\hline$h m n E x 216$ & pCW32, pCW33, pRF4 \\
\hline$h m n E x 660$ & pIL11, pIL12, pRF4 \\
\hline$h m n E x 730$ & pCW94, pIL34, pMH339 \\
\hline$h m n E x 756$ & pCW93, pIL23, pMH2 \\
\hline$h m n E x 762$ & pCW31, pMH28, pRF4 \\
\hline$h m n E x 799$ & pCW34, pIL1, pRF4 \\
\hline$h m n E x 801$ & pKM15, pKM16, pMH91, pMH1 \\
\hline$h m n E x 821$ & pCW32, pCW33, pIL44, \\
& pIL45, pRF4 \\
\hline$h m n E x 824$ & pCW95, pIL34, pIL41 \\
\hline$h m n E x 864$ & pIL43, pIL34, pMH130 \\
\hline$h m n E x 865$ & pCW17, pRF4 \\
\hline$h m n E x 867$ & pIL46, pRF4 \\
\hline$h m n E x 952$ & pMH434, pMH421, pRF4 \\
\hline$h m n E x 953$ & pEL5, pMH457, pRF4 \\
\hline$h m n E x 954$ & pMH419, pMH428, pRF4 \\
\hline$h m n E x 955$ & pMH424, pMH431, pRF4 \\
\hline$h m n E x 1105$ & pCW11, pMH406, pRF4 \\
\hline$h m n E x 1533$ & pMH522, pMH524, pRF4 \\
\hline$h m n E x 1534$ & pMH523, pMH525, pRF4 \\
\hline$h m n E x 1535$ & pCY184, pMH510, pRF4 \\
\hline$h m n E x 1553$ & pMC23, pCY159 \\
\hline$h m n E x 1667$ & pMC33, pMH406, pRF4 \\
\hline$h m n E x 1668$ & pMC34, pMH406, pRF4 \\
\hline
\end{tabular}


bioRxiv preprint doi: https://doi.org/10.1101/393850; this version posted August 16, 2018. The copyright holder for this preprint (which was not certified by peer review) is the author/funder, who has granted bioRxiv a license to display the preprint in perpetuity. It is made available under Low et al. aCC-BY-NC-ND 4.0 International license. Morphogenesis of epithelial neurons

\section{Supplemental Table S3. Plasmids used in this study}

\begin{tabular}{|c|c|c|c|}
\hline Plasmid & Description & Expression & Notes \\
\hline pCW11 & $d y f-7$ pro:DYF-7(ZP-sfGFP) & & $\begin{array}{l}\text { SuperfolderGFP (sfGFP) inserted } \\
\text { at position } 3 \text { (Supp. Fig. S2A) } \\
\text { between ZP domain and CFCS }\end{array}$ \\
\hline pCW12 & $\begin{array}{l}d y f-7 \text { pro:DYF-7(ZPN- } \\
\text { sfGFP-ZPC) }\end{array}$ & & $\begin{array}{l}\text { sfGFP inserted at position } 2 \\
\text { (Supp. Fig. S2A) between ZPN } \\
\text { and ZPC }\end{array}$ \\
\hline pCW13 & $\begin{array}{l}d y f-7 \text { pro:DYF-7(ZP-sfGFP)- } \\
\text { mCherry }\end{array}$ & & \\
\hline pCW17 & $\begin{array}{l}d y f-7 \text { pro:DYF-7(ZP-sfGFP, } \\
\Delta \text { CFCS })\end{array}$ & & $\begin{array}{l}\Delta \text { CFCS as in pMH21 (Heiman } \\
\text { and Shaham, 2009) }\end{array}$ \\
\hline pCW32 & $\begin{array}{l}\text { hsp-16.41pro:DYF-7(ZP- } \\
\text { sfGFP) }\end{array}$ & & $\begin{array}{l}\text { hsp-16.41 pro from pPD49.83 } \\
\text { (Andrew Fire); see pCW11 }\end{array}$ \\
\hline pCW33 & $\begin{array}{l}\text { hsp-16.2pro:DYF-7(ZP- } \\
\text { sfGFP) }\end{array}$ & & $\begin{array}{l}\text { hsp-16.2pro from pPD49.78 } \\
\text { (Andrew Fire); see pCW11 }\end{array}$ \\
\hline pCW34 & pha-4pro:DYF-7(ZP-sfGFP) & embryo gut & $\begin{array}{l}\text { pha-4pro from pMH16 (Heiman } \\
\text { and Shaham, 2009); see pCW11 }\end{array}$ \\
\hline pCW93 & F16F9.3pro:AJM-1-CFP & amphid sheath & $\begin{array}{l}\text { F16F9.3pro from pMH2 } \\
\text { (Heiman and Shaham, 2009); } \\
\text { 2630-bp fragment of AJM-1 } \\
\text { cDNA } \\
\text { (ATGGATGCA..AATCCACTG) } \\
\text { was amplified from wild-type } \\
\text { animals, after (Köppen et al., } \\
\text { 2001) }\end{array}$ \\
\hline pCW94 & odr-1pro:AJM-1-CFP & $\begin{array}{l}\text { amphid AWC } \\
\text { and (weakly) } \\
\text { AWB }\end{array}$ & $\begin{array}{l}\text { odr-Ipro after (L'Etoile and } \\
\text { Bargmann, 2000); see pCW93 }\end{array}$ \\
\hline pCW95 & grl-2pro:AJM-1-CFP & amphid socket & $\begin{array}{l}\text { grl-2pro after (Hao et al., 2006a); } \\
\text { see pCW93 }\end{array}$ \\
\hline pCY159 & unc-122pro:GFP & coelomocytes & \\
\hline pCY184 & gcy-5pro:SAX-7-mApple & amphid ASER & $\begin{array}{l}\text { SAX-7S cDNA (gift from } \\
\text { Hiroyuki Sasakura and Ikue Mori } \\
\text { (Sasakura et al., 2005)) was } \\
\text { fused in frame to mApple }\end{array}$ \\
\hline pDP\#MM051 & unc-119(+) & & (Maduro and Pilgrim, 1995) \\
\hline pEL5 & $f l p-17$ pro:CFP & $\mathrm{BAG}$ & $\begin{array}{l}f l p-17 \text { pro after }(\mathrm{Kim} \text { and } \mathrm{Li}, \\
2004)\end{array}$ \\
\hline pIL1 & pha-4pro:myristyl-mCherry & embryo gut & See pCW34 \\
\hline pIL11 & grl-2pro:DLG-1-YFP & amphid socket & $\begin{array}{l}\text { 558-bp fragment of DLG-1 } \\
\text { cDNA } \\
\text { (ATGCATTCG..GTGGTTGAA) } \\
\text { was amplified from wild-type } \\
\text { animals, after (Lockwood et al., } \\
\text { 2008) }\end{array}$ \\
\hline pIL12 & F16F9.3pro:DLG-1-CFP & amphid sheath & See pCW93, pIL11 \\
\hline pIL23 & F16F9.3pro:ERM-1-YFP & amphid sheath & See pCW93; ERM-1 cDNA \\
\hline
\end{tabular}


bioRxiv preprint doi: https://doi.org/10.1101/393850; this version posted August 16,2018 . The copyright holder for this preprint (which was not certified by peer review) is the author/funder, who has granted bioRxiv a license to display the preprint in perpetuity. It is made available under

\begin{tabular}{|c|c|c|c|}
\hline & & & $\begin{array}{l}\text { sequence was amplified from } \\
\text { yk1728e07 (Yuji Kohara, gift } \\
\text { from Verena Göbel) }\end{array}$ \\
\hline pIL34 & gcy-5pro:AJM-1-YFP & amphid ASER & $\begin{array}{l}\text { gcy-5pro after (Yu et al., 1997); } \\
\text { see pCW93 }\end{array}$ \\
\hline pIL41 & grl-2pro:mApple & amphid socket & $\begin{array}{l}\text { See pCW95; mApple was a gift } \\
\text { from Erin Cram }\end{array}$ \\
\hline pIL43 & gcy-5pro:AJM-1-CFP & amphid ASER & See pIL34, pCW93 \\
\hline pIL44 & $\begin{array}{l}\text { hsp-16.2pro:myristyl- } \\
\text { mCherry }\end{array}$ & & See pCW33 \\
\hline pIL45 & $\begin{array}{l}\text { hsp-16.41 pro:myristyl- } \\
\text { mCherry }\end{array}$ & & See pCW32 \\
\hline pIL46 & $\begin{array}{l}d y f-7 \text { pro:DYF-7 }(\Delta Z \mathrm{P}, \\
\text { sfGFP)-mCherry }\end{array}$ & & $\begin{array}{l}\text { In-frame deletion of } \mathrm{ZP} \text { domain } \\
\text { from } \mathrm{pCW} 13\end{array}$ \\
\hline pKM15 & grl-2pro:YFP & amphid socket & See pCW95 \\
\hline pKM16 & F16F9.3pro:CFP & amphid sheath & See pCW93 \\
\hline $\mathrm{pMC} 23$ & $\begin{array}{l}\text { frm-2pro:frm-2 genomic } \\
\text { region }\end{array}$ & & $\begin{array}{l}4.9 \mathrm{~kb} \text { promoter sequence } \\
\text { (CACTTGTAG..TATTTTCAG) } \\
\text { and } 3.0 \mathrm{~kb} \text { genomic coding } \\
\text { sequence } \\
\text { (ATGTCCTGG..GACTTTTGA) } \\
\text { were amplified from wild-type } \\
\text { animals }\end{array}$ \\
\hline pMC33 & frm-2pro:GFP & & See pMC23 \\
\hline pMC34 & frm-2pro:FRM-2-GFP & & $\begin{array}{l}\text { GFP replacing stop codon of } \\
\text { pMC23 }\end{array}$ \\
\hline pMH2 & F16F9.3pro:mCherry & amphid sheath & (Heiman and Shaham, 2009) \\
\hline pMH28 & dex-1pro:mCherry & $\begin{array}{l}\text { broadly in } \\
\text { embryo head }\end{array}$ & (Heiman and Shaham, 2009) \\
\hline pMH91 & gcy-7pro:mCherry & amphid ASEL & gcy-7pro after (Yu et al., 1997) \\
\hline pMH130 & gcy-5pro:mCherry & amphid ASER & See pIL34 \\
\hline pMH285 & $d y f-7$ pro:DYF-7(sfGFP-ZP) & & $\begin{array}{l}\text { sfGFP inserted at position } 1 \\
\text { (Supp. Fig. S1) between signal } \\
\text { peptide sequence and ZP domain }\end{array}$ \\
\hline pMH339 & odr-1pro:mCherry & $\begin{array}{l}\text { amphid AWC } \\
\text { and (weakly) } \\
\text { AWB }\end{array}$ & See pCW94 \\
\hline pMH406 & $d y f-7$ pro:myristyl-mCherry & & \\
\hline pMH419 & dat-1pro:CFP & CEP & (Gilleland et al., 2015) \\
\hline $\mathrm{pMH} 421$ & flp-8pro:CFP & URX & (Gilleland et al., 2015) \\
\hline pMH424 & $f l p$-3pro:YFP & IL1 & (Gilleland et al., 2015) \\
\hline pMH428 & ser-2prom3pro:YFP & OLL & $\begin{array}{l}\text { ser-2prom } 3 \text { after (Tsalik et al., } \\
2003 \text { ) }\end{array}$ \\
\hline pMH431 & klp-6pro:CFP & IL2 & $\begin{array}{l}\text { klp-6pro after (Peden and Barr, } \\
2005)\end{array}$ \\
\hline pMH434 & tol-1pro:YFP & URY & (Gilleland et al., 2015) \\
\hline pMH457 & ocr-4pro:YFP & OLQ & $\begin{array}{l}\text { ocr-4pro after (Tobin et al., } \\
\text { 2002) }\end{array}$ \\
\hline pMH510 & gcy-5pro:SAX-7هcyt-sfGFP & amphid ASER & SAX-7S cDNA cytoplasmic tail \\
\hline
\end{tabular}


bioRxiv preprint doi: https://doi.org/10.1101/393850; this version posted August 16,2018 . The copyright holder for this preprint (which was not certified by peer review) is the author/funder, who has granted bioRxiv a license to display the preprint in perpetuity. It is made available under Low et al. aCC-BY-NC-ND 4.0 International license. Morphogenesis of epithelial neurons

\begin{tabular}{|l|l|l|l|}
\hline & & & $\begin{array}{l}\text { was deleted and replaced with } \\
\text { superfolderGFP ([..CRQRG]- } \\
\text { [MSKGE..]) }\end{array}$ \\
\hline pMH522 & F16F9.3pro:SAX-7-mApple & amphid sheath & See pCY184 \\
\hline pMH523 & grl-2pro:SAX-7-mApple & amphid socket & See pCY184 \\
\hline pMH524 & $\begin{array}{l}\text { F16F9.3pro:SAX-7Acyt- } \\
\text { sfGFP }\end{array}$ & amphid sheath & See pMH510 \\
\hline pMH525 & grl-2pro:SAX-7Dcyt-sfGFP & amphid socket & See pMH510 \\
\hline pRF4 & rol-6(su1006) & & (Mello et al., 1991) \\
\hline
\end{tabular}



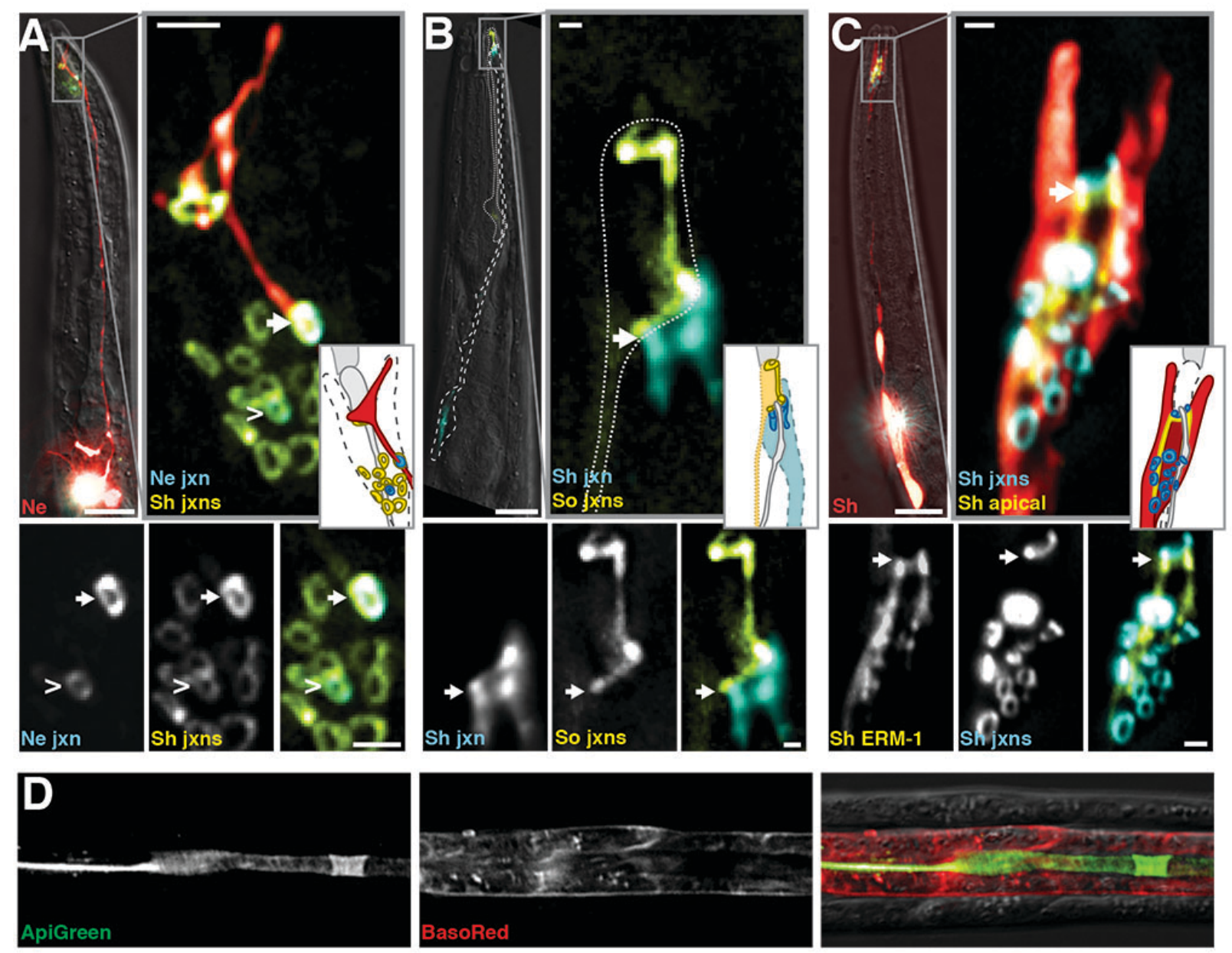

\section{Supporting Figure S1. Markers for tight junctions and apical surfaces}

(A, B) Overlap of neuron:sheath junctions as in Fig. 1, except (A) showing amphid neurons

AWC (arrow) and AWB (carat) instead of ASE (Ne, AWC neuron (red, odr-1pro:RFP, only

AWC is shown as AWB expression is dimmer and not visible here); Ne jxn, neuron junctions

(blue, odr-1pro:AJM-1-CFP); Sh jxns, sheath junctions (yellow, F16F9.3pro:AJM-1-YFP)), and

(B) showing the tight junction marker DLG-1 instead of AJM-1 (Sh jxn, sheath junctions (blue,

F16F9.3pro:AJM-1-CFP, only sheath:socket junction is shown as sheath:neuron junctions are outside the region of interest); So jxn, socket glial junctions (yellow, grl-2pro:DLG-1-YFP)). (C)

The apical cytoskelal-associated protein ERM-1 localizes to the outward-facing surface of the sheath (arrow). Sh, sheath glial cell (red, F16F9.3pro:mCherry); Sh jxns, sheath junctions (blue, F16F9.3pro:AJM-1-CFP); Sh ERM-1 (yellow, F16F9.3pro:ERM-1-YFP). (D) Expression of 
bioRxiv preprint doi: https://doi.org/10.1101/393850; this version posted August 16, 2018. The copyright holder for this preprint (which was not certified by peer review) is the author/funder, who has granted bioRxiv a license to display the preprint in perpetuity. It is made available under Low et al.

apical marker ApiGreen and basolateral marker BasoRed in gut, a well-studied model

epithelium. The lumen (apical) surface of the gut exhibits localization of ApiGreen and exclusion

of BasoRed. Scale bars: $10 \mu \mathrm{m}$, main panels; $1 \mu \mathrm{m}$, magnified insets. 

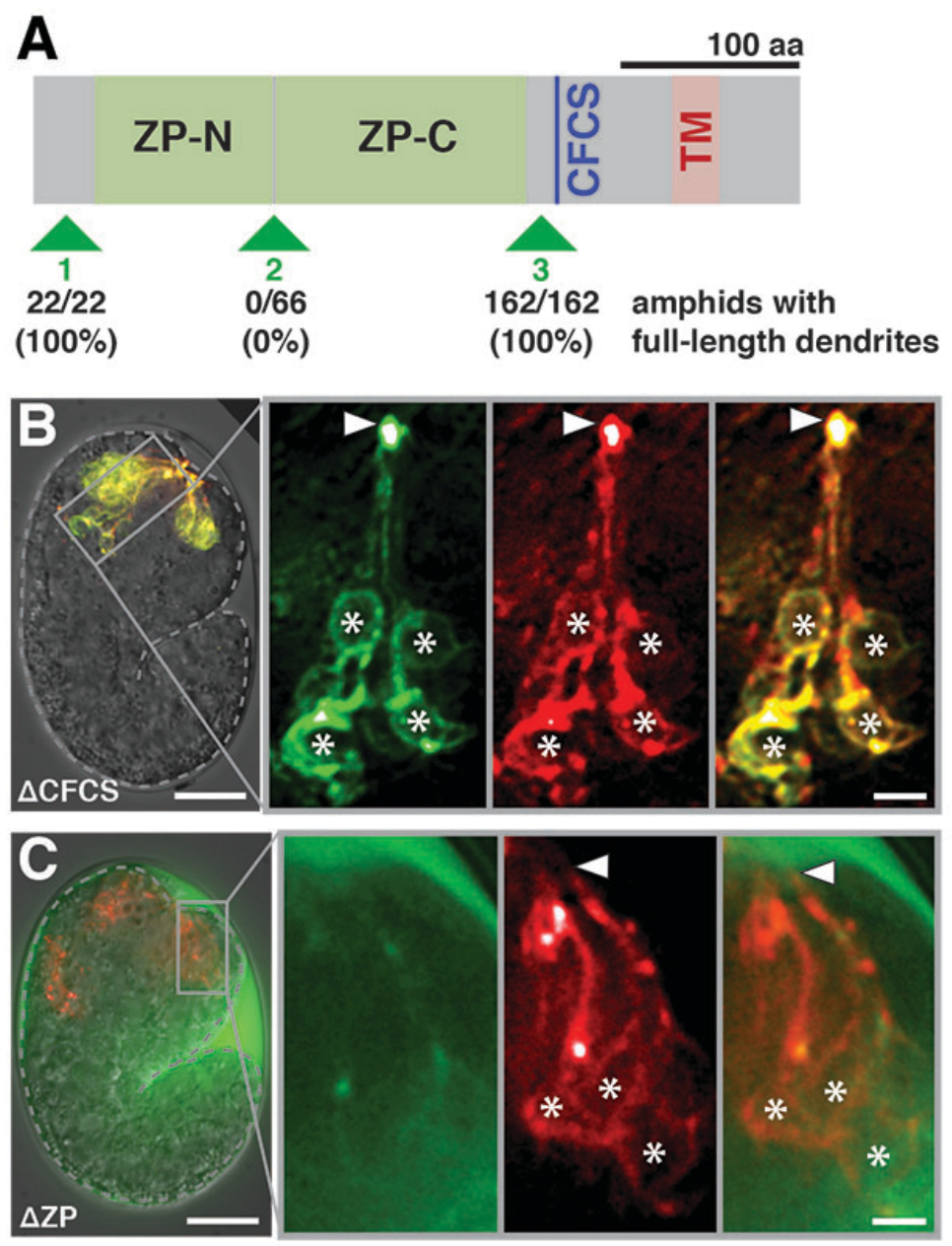

\section{Supporting Figure S2. Localization of DYF-7 in vivo}

(A) SuperfolderGFP coding sequence was inserted into the DYF-7 cDNA at positions 1, 2, or 3 as indicated (pMH285, $\mathrm{pCW} 12$, and $\mathrm{pCW} 11$, respectively; Table S1). These constructs were introduced into a strain bearing $d y f-7(n s 119)$ and an amphid neuron marker (AWC, odrlpro:RFP) and scored for rescue of dendrite extension defects. CFCS, consensus furin cleavage site; TM, transmembrane segment. (B,C) Live, intact embryos expressing sfGFP-DYF-7mCherry in sensory neurons ( $d y f-7$ pro) at the time of dendrite extension, as in Fig. 2, but with constructs that are (B) lacking the CFCS ( $\triangle \mathrm{CFCS}$ ) or (C) ZP domain ( $\triangle \mathrm{ZP})$. sfGFP, green; mCherry, red; arrowheads, dendrite tips; asterisks, neuron cell bodies. Scale bars: $10 \mu \mathrm{m}$, main panels; $2 \mu \mathrm{m}$, magnified insets. 